\title{
Stereoselective Synthesis of the Octahydronaphthalene Unit of Integramycin via an Intramolecular Diels-Alder Reaction
}

\author{
Thomas A. Dineen and William R. Roush* \\ Department of Chemistry, University of Michigan, Ann Arbor, MI, 48109 \\ e-mail: roush@umich.edu
}

Supporting Information 
General Experimental Details. All reaction solvents were purified before use. Tetrahydrofuran, dichloromethane, and toluene were purified by passing through a solvent column composed of activated A-1 alumina. Unless indicated, all chemicals were used as purchased without further purification.

Proton nuclear magnetic resonance ( $\left({ }^{1} \mathrm{H}\right.$ NMR) spectra and carbon-13 $\left({ }^{13} \mathrm{C}\right)$ NMR spectra were recorded on a Varian Inova-500 spectrometer at $500 \mathrm{MHz}$ and $125 \mathrm{MHz}$ respectively. The proton signal of residual, non-deuterated solvent $\left(\square 7.26 \mathrm{ppm}\right.$ for $\left.\mathrm{CHCl}_{3}\right)$ was used as an internal reference for ${ }^{1} \mathrm{H}$ spectra. For ${ }^{13} \mathrm{C}$ spectra, chemical shifts are reported relative to the $777.00 \mathrm{ppm}$ resonance of $\mathrm{CDCl}_{3}$. Coupling constants are reported in $\mathrm{Hz}$. Infrared (IR) spectra were recorded as thin films on a Perkin-Elmer Spectrum 1000 FTIR. Mass spectra were recorded on a ZVG 70-250-S spectrometer manufactured by Micromass Corp. (Manchester UK).

Analytical thin layer chromatography (TLC) was performed on Kieselgel $60 \mathrm{~F}_{254}$ glass plates precoated with a $0.25 \mathrm{~mm}$ thickness of silica gel. The TLC plates were visualized with UV light and/or by staining with $p$-anisaldehyde solution ( $p$-anisaldehyde in ethanolic sulfuric acid). Column chromatography was performed using Kieselgel 60 (230-400 mesh) silica gel.

HPLC purifications were performed using an HPLC system composed of two Rainin HPXL pumps connected to various Dynamax ${ }^{\square}$ axial compression columns packed with Rainin $60 \AA$ irregular silica gel. Samples were loaded into the system with a $2 \mathrm{~mL}$ Rheodyne 7125 injector and were detected using a Rainin Dynamax ${ }^{\square}$ UV-C detector. Integration of the various signals was performed using the reprocessing program within the Dynamax ${ }^{\square}$ HPLC Method Manager. 


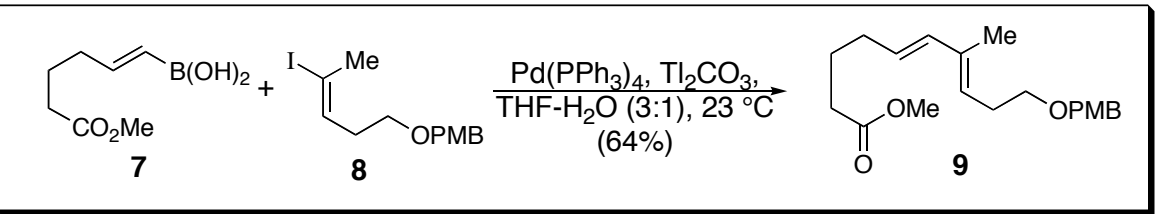

(5E,7E)-10-(4-methoxybenzyloxy)-7-methyl-deca-5,7-dienoic acid methyl ester (9). To a stirring solution of vinyl boronic acid $7(7.59 \mathrm{mmol})$ and vinyl iodide $8(5.06 \mathrm{mmol})$ in an $\operatorname{Ar}(\mathrm{g})$ degassed 3:1 mixture of THF- $\mathrm{H}_{2} \mathrm{O}(24 \mathrm{~mL})$ was added $\mathrm{Pd}\left(\mathrm{PPh}_{3}\right)_{4}(877 \mathrm{mg}, 0.76 \mathrm{mmol})$, followed by $\mathrm{Tl}_{2} \mathrm{CO}_{3}(4.70 \mathrm{~g}, 10.1 \mathrm{mmol})$. The resulting mixture was stirred under $\mathrm{Ar}(\mathrm{g})$ for $30 \mathrm{~min}$, after which it was added to 1:1 mixture of EtOAc-Hexane $(50 \mathrm{~mL})$ and filtered through celite. The filtrate was washed with brine, dried over $\mathrm{MgSO}_{4}$, filtered and evaporated. The crude product was purified by column chromatography on $\mathrm{SiO}_{2}(15 \% \mathrm{EtOAc/Hexane})$ to give $1.08 \mathrm{~g}(64 \%)$ of diene 9 as a yellow oil: ); ${ }^{1} \mathrm{H} \mathrm{NMR}\left(\mathrm{CDCl}_{3}, 400 \mathrm{MHz}\right) \square 7.23-7.21$ (m, $\left.2 \mathrm{H}\right), 6.85-6.82$ (m, $\left.2 \mathrm{H}\right), 6.02$ (d, J = $15.4 \mathrm{~Hz}, 1$ H), $5.48(\mathrm{dt}, \mathrm{J}=15.8,7.0 \mathrm{~Hz}, 1 \mathrm{H}), 5.34(\mathrm{t}, \mathrm{J}=7.3 \mathrm{~Hz}, 1 \mathrm{H}), 4.41(\mathrm{~s}, 2 \mathrm{H}), 3.76(\mathrm{~s}, 3 \mathrm{H}), 3.62(\mathrm{~s}, 3$ H), 3.42 (t, J = 7.0 Hz, 2 H), 2.39 (q, J = 7.3 Hz, 2 H), $2.27(\mathrm{t}, \mathrm{J}=7.3 \mathrm{~Hz}, 2 \mathrm{H})$, 2.11-2.06 (m, $2 \mathrm{H})$, 1.73-1.68 (m, $5 \mathrm{H}) ;{ }^{13} \mathrm{C} \mathrm{NMR}\left(\mathrm{CDCl}_{3}, 100 \mathrm{MHz}\right) \square 171.4,159.1,135.0,131.1,130.5,129.2,126.5$, $113.7,72.5,69.4,55.2,51.4,33.3,32.1,31.8,28.8,24.7,12.5$; IR (neat) 2949, 2856, 1737, 1613, 1513, 1437, 1247, 1172, 1096, 1036; HRMS (ESI) for $\mathrm{C}_{20} \mathrm{H}_{28} \mathrm{O}_{4} \mathrm{Na}[\mathrm{M}+\mathrm{Na}]^{+}$calcd. 355.1885, found 355.1879 .

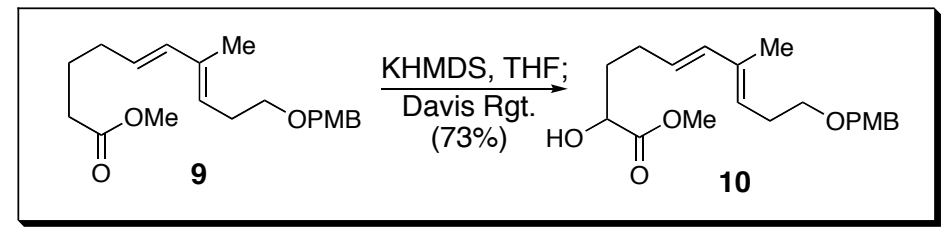

(5E,7E)-2-hydroxy-10-(4-methoxybenzyloxy)-7-methyl-deca-5,7-dienoic acid methyl ester (10). To a cooled solution $\left(-78^{\circ} \mathrm{C}\right)$ of KHMDS $(652 \mathrm{mg}, 3.27 \mathrm{mmol})$ in $\mathrm{THF}(50 \mathrm{~mL})$ was added a solution of methyl ester $9(725 \mathrm{mg}, 2.18 \mathrm{mmol})$ in THF (1 ml) dropwise over $5 \mathrm{~min}$. The 
resulting mixture was stirred for $30 \mathrm{~min}$, then a solution of racemic trans-2-(phenylsulfonyl)-3phenyloxaziridine in THF $(50 \mathrm{~mL})$ was added dropwise over $30 \mathrm{~min}$. The reaction was stirred for an additional $1 \mathrm{~h}$, after which a saturated aqueous solution of $\mathrm{NH}_{4} \mathrm{Cl}(30 \mathrm{~mL})$ was added. The mixture was warmed to room temperature and extracted with $\mathrm{Et}_{2} \mathrm{O}(4 \times 15 \mathrm{~mL})$. The combined organic extracts were washed with brine, dried over $\mathrm{MgSO}_{4}$, filtered, and evaporated. The crude product was purified by column chromatography on $\mathrm{SiO}_{2}(35 \% \mathrm{EtOAc} / \mathrm{Hexane})$ to give $554 \mathrm{mg}$ (73\%) of 10 as a clear oil: ${ }^{1} \mathrm{H}$ NMR $\left(\mathrm{CDCl}_{3}, 400 \mathrm{MHz}\right) \square 7.27-7.25$ (m, $\left.2 \mathrm{H}\right), 6.89-6.86(\mathrm{~m}, 2 \mathrm{H})$, $6.10(\mathrm{~d}, \mathrm{~J}=15.7 \mathrm{~Hz}, 1 \mathrm{H}), 5.55(\mathrm{dt}, \mathrm{J}=15.4,7.0 \mathrm{~Hz}, 1 \mathrm{H}), 5.40(\mathrm{t}, \mathrm{J}=7.0 \mathrm{~Hz}, 1 \mathrm{H}), 4.22-4.18(\mathrm{~m}, 1$ H), $3.80(\mathrm{~s}, 3 \mathrm{H}), 3.78(\mathrm{~s}, 3 \mathrm{H}), 3.46(\mathrm{t}, \mathrm{J}=7.0 \mathrm{~Hz}, 2 \mathrm{H}), 2.73(\mathrm{~d}, \mathrm{~J}=5.1 \mathrm{~Hz}, 1 \mathrm{H}), 2.43(\mathrm{q}, \mathrm{J}=7.0$ $\mathrm{Hz}, 2 \mathrm{H}), 2.29-2.18$ (m, $2 \mathrm{H}), 1.94-1.85(\mathrm{~m}, 1 \mathrm{H}), 1.78-1.70(\mathrm{~m}, 4 \mathrm{H}) ;{ }^{13} \mathrm{C} \mathrm{NMR}\left(\mathrm{CDCl}_{3}, 100 \mathrm{MHz}\right) \square$ $175.7,159.1,135.7,135.0,130.5,129.2,126.7,126.1,113.7,72.5,69.8,69.4,55.3,52.5,34.2$, 28.9, 28.0, 12.5; IR (neat) 3470, 2952, 2856, 1739, 1613, 1514, 1442, 1248, 1098, 1035; HRMS (ESI) for $\mathrm{C}_{20} \mathrm{H}_{28} \mathrm{O}_{5} \mathrm{Na}[\mathrm{M}+\mathrm{Na}]^{+}$calcd. 371.1836, found 371.1843. Anal. Calcd. For $\mathrm{C}_{20} \mathrm{H}_{28} \mathrm{O}_{5}: \mathrm{C}$, 68.94; H, 8.10. Found: C, 68.88; H, 8.05.

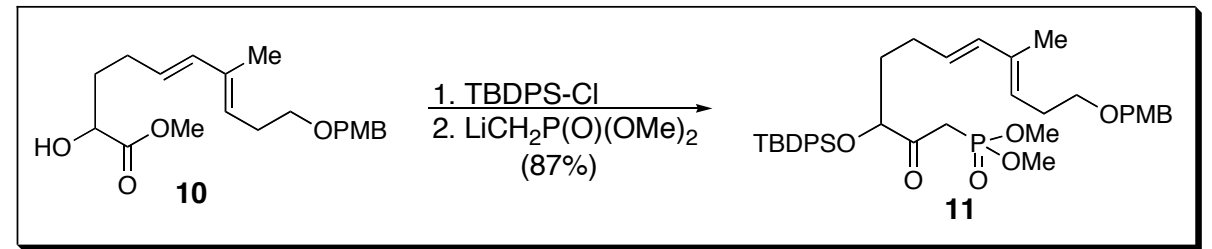

(6E,8E)-3-(tert-butyldiphenylsilyloxy)-11-(4-methoxybenzyloxy)-8-methyl-2-oxo-

undeca-6,8-dienyl-dimethylphosphonate (11). To a solution of $\square$-hydroxy methyl ester 10 (391 $\mathrm{mg}, 1.12 \mathrm{mmol})$ in DMF (0.5 mL) was added TBDPS-Cl $(0.31 \mathrm{~mL}, 1.18 \mathrm{mmol})$, imidazole $(84 \mathrm{mg}$, $1.23 \mathrm{mmol}$ ), and DMAP (14 mg, $0.11 \mathrm{mmol})$. The resulting mixture was stirred overnight, after which time it was added to water $(10 \mathrm{~mL})$ and extracted with $\mathrm{Et}_{2} \mathrm{O}(3 \times 5 \mathrm{~mL})$. The combined organic extracts were washed with brine, dried over $\mathrm{MgSO}_{4}$, filtered, and evaporated. The crude 
product could only be partially purified by passing through a short column of $\mathrm{SiO}_{2}(10 \%$ EtOAc/Hexane) to give $599 \mathrm{mg}$ of silyl ether $\mathbf{2 1}$ with ca. 5-10\% of TBDPS-by products. A separate flask was charged with dimethyl methylphosphonate $(0.33 \mathrm{~mL}, 3.06 \mathrm{mmol})$ in THF $(8 \mathrm{~mL})$ and cooled to $-78{ }^{\circ} \mathrm{C}$. A $2.45 \mathrm{M}$ solution of $n \mathrm{BuLi}$ in hexane $(1 \mathrm{~mL}, 2.45 \mathrm{mmol})$ was added dropwise to the phosphonate solution and the resulting mixture was stirred for $30 \mathrm{~min}$. Compound $\mathbf{1 0}$ was redissolved in THF $(1 \mathrm{~mL})$ and added dropwise to the phosphonate anion solution with a THF (1 $\mathrm{mL})$ flask wash. The reaction was stirred for $2.5 \mathrm{~h}$, and a $10 \%$ aqueous solution of $\mathrm{K}_{2} \mathrm{HPO}_{4}(10 \mathrm{~mL})$ was added. The mixture was warmed to room temperature and extracted with $\mathrm{Et}_{2} \mathrm{O}(5 \times 10 \mathrm{~mL})$. The combined organic extracts were washed with brine, dried over $\mathrm{MgSO}_{4}$, filtered, and evaporated. Purification of the crude product by column chromatography on $\mathrm{SiO}_{2}(65 \%$ EtOAc/Hexane) gave $570 \mathrm{mg}(86 \%)$ of 11 as a clear oil: ${ }^{1} \mathrm{H}$ NMR $\left(\mathrm{CDCl}_{3}, 400 \mathrm{MHz}\right) \square 7.60-7.56(\mathrm{~m}, 4 \mathrm{H}), 7.42-7.31(\mathrm{~m}$, $6 \mathrm{H}), 7.22(\mathrm{~d}, \mathrm{~J}=8.8 \mathrm{~Hz}, 2 \mathrm{H}), 6.83(\mathrm{~d}, \mathrm{~J}=8.8 \mathrm{~Hz}, 2 \mathrm{H}), 5.88(\mathrm{~d}, \mathrm{~J}=15.7 \mathrm{~Hz}, 1 \mathrm{H}), 5.32-5.25(\mathrm{~m}, 2$ H), $4.41(\mathrm{~s}, 2 \mathrm{H}), 4.18(\mathrm{t}, \mathrm{J}=6.2 \mathrm{~Hz}, 1 \mathrm{H}), 3.41(\mathrm{t}, \mathrm{J}=7.0 \mathrm{~Hz}, 2 \mathrm{H}), 3.28(\mathrm{dd}, \mathrm{J}=19.8,15.4 \mathrm{~Hz}, 1$ H), $2.86(\mathrm{dd}, \mathrm{J}=22.0,15.4 \mathrm{~Hz}, 1 \mathrm{H}), 2.37(\mathrm{q}, \mathrm{J}=7.0 \mathrm{~Hz}, 2 \mathrm{H}), 3.76(\mathrm{~s}, 3 \mathrm{H}), 3.67$ (dd, J = 11.4, 3.7 $\mathrm{Hz}, 6 \mathrm{H}), 2.06-1.88$ (m, $2 \mathrm{H}), 1.69-1.63$ (m, $2 \mathrm{H}), 1.61$ (s, $3 \mathrm{H}), 1.07$ (s, $9 \mathrm{H}){ }^{13} \mathrm{C}$ NMR $\left(\mathrm{CDCl}_{3}, 100\right.$ MHz) $\square 203.5,159.1,135.8,135.4,134.9,133.1,132.6,130.5,130.0,129.2,127.8,127.7,126.6$, $126.1,113.7,78.8,72.5,69.4,55.2,52.8,36.0,34.6,34.0,28.9,27.5,26.9,19.3,12.5$; IR (neat) 2953, 2933, 2857, 1724, 1612, 1513, 1428, 1250, 1181, 1112, 1034, 822, 703; HRMS (ESI) for $\mathrm{C}_{38} \mathrm{H}_{51} \mathrm{O}_{7} \mathrm{PSiNa}[\mathrm{M}+\mathrm{Na}]^{+}$calcd. 701.3039, found 701.3055. Anal. Calcd. For $\mathrm{C}_{38} \mathrm{H}_{51} \mathrm{O}_{7} \mathrm{PSi}: \mathrm{C}, 67.23$; H, 7.57. Found: C, 67.32; H, 7.44. 


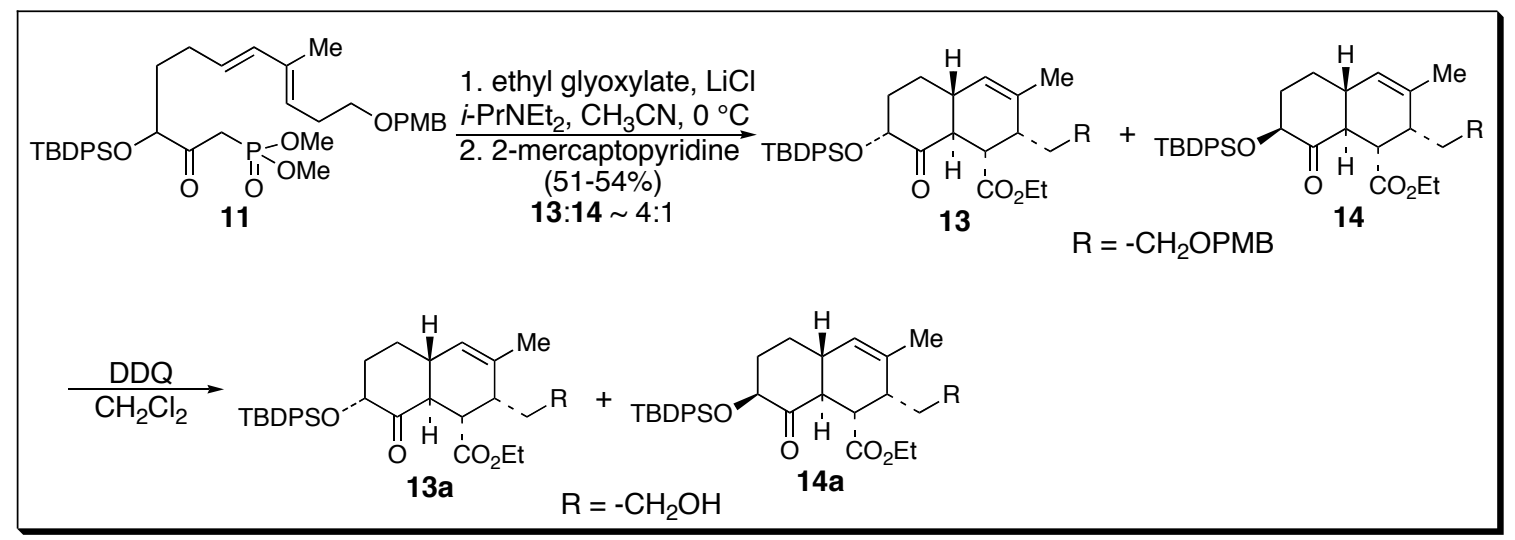

IMDA Reaction of 12. To a stirred solution of $\square$-ketophosphonate 11 (50 mg, $74 \square \mathrm{mol})$ in $\mathrm{CH}_{3} \mathrm{CN}(2.4 \mathrm{~mL})$ was added $\mathrm{LiCl}(31 \mathrm{mg}, 0.74 \square \mathrm{mol})$, and the resulting mixture was cooled to $0{ }^{\circ} \mathrm{C}$. $i \operatorname{PrNEt}_{2}(14 \square \mathrm{L}, 81 \square \mathrm{mol})$ was added and the reaction stirred for $5 \mathrm{~min}$. Ethyl glyoxylate $(71 \square \mathrm{L}$, $0.29 \mathrm{mmol}$ ) was added and the reaction was stirred for $15 \mathrm{~min}$. After this time, 2 crystals of 2 mercaptopyridine were added. After stirring for an additional $30 \mathrm{~min}$, a saturated aqueous solution of $\mathrm{NH}_{4} \mathrm{Cl}(5 \mathrm{~mL})$ was added, and the resulting mixture was extracted with $\mathrm{CH}_{2} \mathrm{Cl}_{2}(3 \times 5 \mathrm{~mL})$. The combined organic extracts were washed with brine, dried over $\mathrm{Na}_{2} \mathrm{SO}_{4}$, and evaporated. The crude material was purified by column chromatography on $\mathrm{SiO}_{2}(25 \%$ EtOAc/Hexane) to give $26 \mathrm{mg}$ (54\%) of a mixture of cycloadducts 13 and 14. This mixture was redissolved in $\mathrm{CH}_{2} \mathrm{Cl}_{2}(0.5 \mathrm{~mL})$ and $\mathrm{pH} 7$ buffer $(0.025 \mathrm{ml})$ and cooled to $0{ }^{\circ} \mathrm{C}$. DDQ $(12.1 \mathrm{mg}, 53.1 \square \mathrm{mol})$ was added, and the reaction was stirred for $2 \mathrm{~h}$. A saturated aqueous $\mathrm{NaHCO}_{3}$ solution $(10 \mathrm{~mL})$ was added, and the mixture was extracted with $\mathrm{Et}_{2} \mathrm{O}(3 \times 8 \mathrm{~mL})$. The combined organic extracts were washed with brine, dried over $\mathrm{MgSO}_{4}$, filtered, and evaporated. The crude material was purified by preparatory thinlayer chromatography on $\mathrm{SiO}_{2}(30 \% \mathrm{EtOAc} / \mathrm{Hexane})$ to give $17.0 \mathrm{mg}(72 \%)$ of $\mathbf{1 3 a}$ and $5.7 \mathrm{mg}$ of 14a $(24 \%)$ as clear oils. 


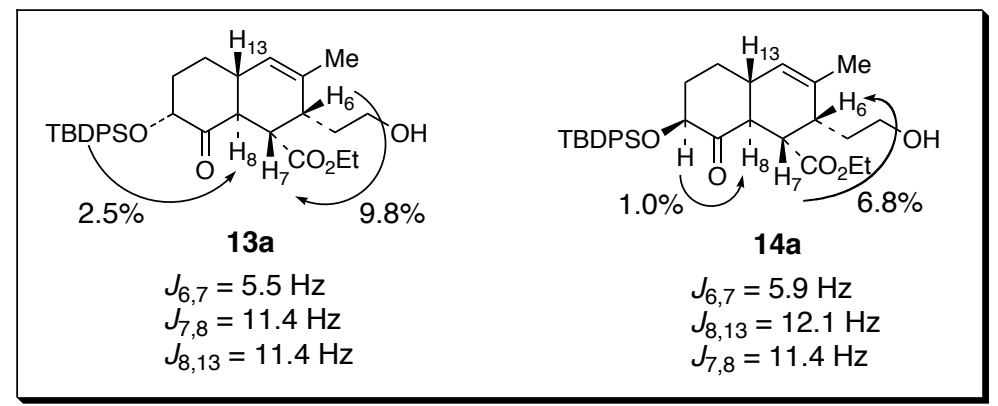

Data for 13a: ${ }^{1} \mathrm{H}$ NMR $\left(\mathrm{CDCl}_{3}, 500 \mathrm{MHz}\right) \square 7.69$ (d, J = 7.0 Hz, $\left.2 \mathrm{H}\right), 7.62$ (d, J = 6.6 Hz, 2 H), 7.44-7.36 (m, $6 \mathrm{H}), 5.29$ (s, $1 \mathrm{H}), 4.32-4.24(\mathrm{~m}, 1 \mathrm{H}), 4.13-4.05$ (m, $2 \mathrm{H}), 3.66-3.56(\mathrm{~m}, 2 \mathrm{H})$, $3.52(\mathrm{t}, \mathrm{J}=11.4 \mathrm{~Hz}, 1 \mathrm{H}), 2.85(\mathrm{dd}, \mathrm{J}=11.4,5.5 \mathrm{~Hz}, 1 \mathrm{H}), 2.48$ (br. s., $1 \mathrm{H}), 2.22-1.80(\mathrm{~m}, 3 \mathrm{H})$, $1.77(\mathrm{~s}, 3 \mathrm{H}), 1.66-1.44(5 \mathrm{H}), 1.28(\mathrm{t}, \mathrm{J}=7.3 \mathrm{~Hz}, 3 \mathrm{H}), 1.12(\mathrm{~s}, 9 \mathrm{H}) ;{ }^{13} \mathrm{C} \mathrm{NMR}\left(\mathrm{CDCl}_{3}, 100 \mathrm{MHz}\right)$ $\square 136.3,135.9,135.7,129.9,129.8,127.7,127.6,125.3,76.4,61.7,60.4,46.0,45.0,43.4,38.1$, 35.3, 33.6, 26.9, 21.8, 19.3, 14.2; IR (neat) 3445, 3072, 3049, 2931, 3858, 1729, 1428, 1182, 1112 , 1092, 702; HRMS (ESI) for $\mathrm{C}_{32} \mathrm{H}_{42} \mathrm{O}_{5} \mathrm{SiNa}[\mathrm{M}+\mathrm{Na}]^{+}$calcd. 557.2699, found 557.2697.

Data for 14a: ${ }^{1} \mathrm{H}$ NMR $\left(\mathrm{CDCl}_{3}, 500 \mathrm{MHz}\right) \square 7.69-7.64(\mathrm{~m}, 4 \mathrm{H})$, 7.44-7.36 (m $\left.6 \mathrm{H}\right), 5.23$ (s, $1 \mathrm{H}), 4.35(\mathrm{dd}, \mathrm{J}=11.0,7.3 \mathrm{~Hz}, 1 \mathrm{H}), 4.29-4.21(\mathrm{~m}, 1 \mathrm{H}), 4.11-4.03(\mathrm{~m}, 1 \mathrm{H}), 3.47$ (td, J = 5.9, 2.6 Hz, $1 \mathrm{H}), 2.86(\mathrm{dd}, \mathrm{J}=11.4,5.9 \mathrm{~Hz}, 1 \mathrm{H}), 2.43$ (t, J = $11.7 \mathrm{~Hz}, 2 \mathrm{H}), 2.18-2.12$ (m, $1 \mathrm{H}), 2.01$ (br. T, $\mathrm{J}=12.8 \mathrm{~Hz}, 1 \mathrm{H}), 1.79-1.68(\mathrm{~m}, 3 \mathrm{H}), 1.69$ (s, $3 \mathrm{H}), 1.62-1.52$ (br. $\mathrm{S}, 3 \mathrm{H}), 1.51-1.43$ (m, $1 \mathrm{H}), 1.28$ $(\mathrm{t}, \mathrm{J}=7.3 \mathrm{~Hz}, 3 \mathrm{H}), 1.08(\mathrm{~s}, 9 \mathrm{H}) ;{ }^{13} \mathrm{C} \mathrm{NMR}\left(\mathrm{CDCl}_{3}, 100 \mathrm{MHz}\right) \square 207.9,174.0,136.2,135.8,135.7$, $134.2,129.6,127.6,124.6,61.3,60.5,48.5,43.6,43.2,40.4,37.6,37.2,33.4,30.2,26.8,21.8,19.4$, 14.1; IR (neat) 3358, 2953, 2924, 2854, 1730, 1459, 1377; HRMS (ESI) for $\mathrm{C}_{32} \mathrm{H}_{42} \mathrm{O}_{5} \mathrm{SiNa}[\mathrm{M}+\mathrm{Na}]^{+}$ calcd. 557.2699, found 557.2675. 


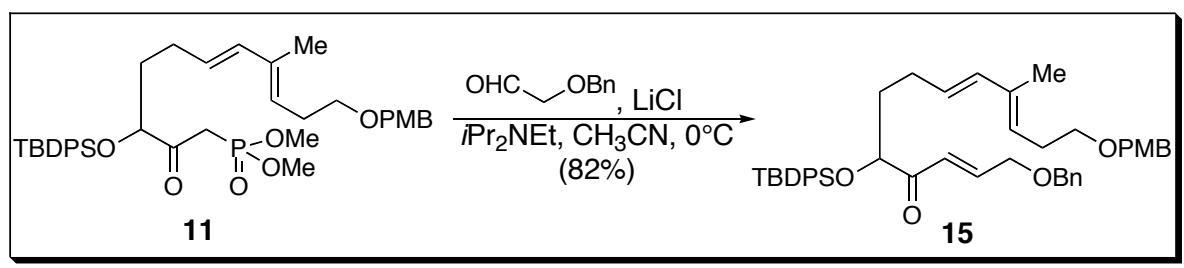

(2E,8E,10E)-1-benzyloxy-5-(tert-butyldiphenylsilyloxy)-13-(4-methoxybenzyloxy)-10-

methyl-trideca-2,8,10-trien-4-one (15). $\mathrm{LiCl}(350 \mathrm{mg}, 8.25 \mathrm{mmol})$ was added to a stirred solution of $\square$-ketophosphonate $11(560 \mathrm{mg}, 0.83 \mathrm{mmol})$ in $\mathrm{CH}_{3} \mathrm{CN}(25 \mathrm{~mL})$, and the resulting mixture was cooled to $0{ }^{\circ} \mathrm{C}$. $i \operatorname{PrNEt}_{2}(0.16 \mathrm{~mL}, 0.91 \mathrm{mmol})$ was added and the mixture was stirred for 5 min before benzyloxy acetaldehyde $(0.23 \mathrm{~mL}, 1.65 \mathrm{mmol})$ was added dropwise. The reaction was stirred for $2 \mathrm{~h}$, quenched with a saturated aqueous solution of $\mathrm{NH}_{4} \mathrm{Cl}(15 \mathrm{~mL})$, and extracted with $\mathrm{CH}_{2} \mathrm{Cl}_{2}$ (3 x $10 \mathrm{~mL}$ ). The combined organic extracts were washed with brine, dried over $\mathrm{MgSO}_{4}$, filtered, and evaporated. Purification of the crude product by column chromatography on $\mathrm{SiO}_{2}(15 \%$ EtOAc/Hexane) gave $473 \mathrm{mg}(82 \%)$ of 15 as a clear oil: ${ }^{1} \mathrm{H} \mathrm{NMR}\left(\mathrm{CDCl}_{3}, 500 \mathrm{MHz}\right) \square 7.61(\mathrm{~d}, \mathrm{~J}=$ $7.0 \mathrm{~Hz}, 2 \mathrm{H}), 7.56(\mathrm{~d}, \mathrm{~J}=7.0 \mathrm{~Hz}, 2 \mathrm{H}), 7.39-7.22(\mathrm{~m}, 12 \mathrm{H}), 6.86-6.82(\mathrm{~m}, 5 \mathrm{H}), 5.91(\mathrm{~d}, \mathrm{~J}=15.4$ $\mathrm{Hz}, 1 \mathrm{H}), 5.36(\mathrm{t}, \mathrm{J}=6.6 \mathrm{~Hz}, 1 \mathrm{H}), 5.32-5.28(\mathrm{~m}, 1 \mathrm{H}), 4.50(\mathrm{~s}, 2 \mathrm{H}), 4.41(\mathrm{~s}, 2 \mathrm{H}), 4.23(\mathrm{t}, \mathrm{J}=5.9$ Hz, 1 H), 4.12 (d, J = 1.8 Hz, 2 H), 3.77 (s, 3 H), 3.41 (t, J = 7.0 Hz, 2 H), 2.38 (q, J = 7.0 Hz, 2H), 2.05-1.97 (m, $2 \mathrm{H}), 1.76-1.60(\mathrm{~m}, 2 \mathrm{H}), 1.62(\mathrm{~s}, 3 \mathrm{H}), 1.07(\mathrm{~s}, 9 \mathrm{H}) ;{ }^{13} \mathrm{C} \mathrm{NMR}\left(\mathrm{CDCl}_{3}, 100 \mathrm{MHz}\right)$ $\square 200.3,159.1,143.2,137.8,135.9,135.8,135.2,135.1,133.5,132.9,130.5,129.8,129.2,128.4$, $127.7,127.6,127.5,126.5,126.4,124.1,113.7,78.1,72.7,72.5,69.5,69.0,55.3,34.9,28.8,27.6$, 27.0, 19.3, 12.5; IR (neat) 3070, 3030, 2932, 2894, 2857, 1695, 1630, 1613, 1428, 1248, 1112; HRMS (ESI) for $\mathrm{C}_{45} \mathrm{H}_{54} \mathrm{O}_{5} \mathrm{SiNa}[\mathrm{M}+\mathrm{Na}]^{+}$calcd. 725.3638, found 725.3636. 


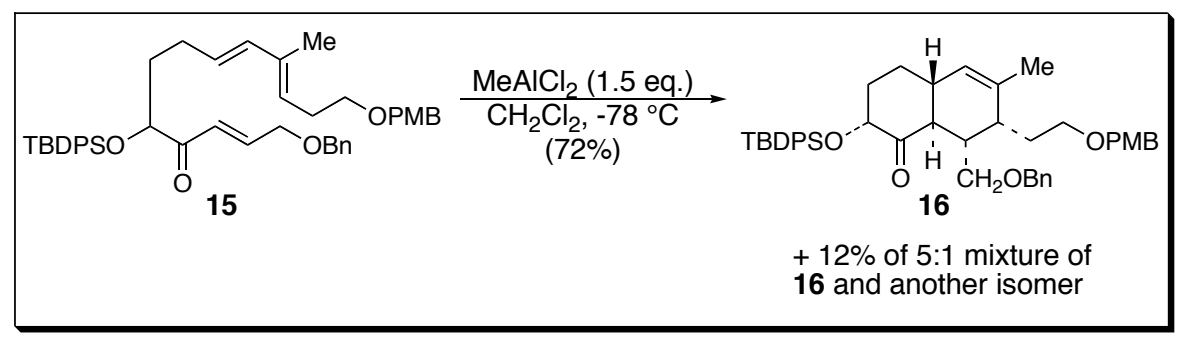

rac-(2R,4aR,7R,8S,8aS)-8-benzyloxymethyl-2-(tert-butyldiphenylsilyloxy)-7-[2-(4-

methoxybenzyloxy)-ethyl]-6-methyl-4,4a,7,8,8a-hexahydro-2H-naphalen-1-one (16). To a cooled ($\left.78{ }^{\circ} \mathrm{C}\right)$ solution of triene $15(462 \mathrm{mg}, 0.66 \mathrm{mmol})$ in $\mathrm{CH}_{2} \mathrm{Cl}_{2}(65 \mathrm{~mL})$ was added dropwise a solution of $\mathrm{MeAlCl}_{2}(0.79 \mathrm{~mL}, 0.79 \mathrm{mmol})$ in hexanes. The reaction was stirred for $1.5 \mathrm{~h}$, then a saturated aqueous solution of Rochelle's salt $(50 \mathrm{~mL})$ was added and the resulting mixture warmed to room temperature. The aqueous layer was extracted with $\mathrm{Et}_{2} \mathrm{O}(2 \times 100 \mathrm{~mL})$. The combined organic extracts were washed with brine, dried over $\mathrm{MgSO}_{4}$, filtered and evaporated. Purification of the crude product by column chromatography on $\mathrm{SiO}_{2}(5 \%$ EtOAc/Hexane) gave $333 \mathrm{mg}(72 \%)$ of 16 and $57 \mathrm{mg}(12 \%)$ of impure 16. Data for 16: ${ }^{1} \mathrm{H}$ NMR $\left(\mathrm{CDCl}_{3}, 500 \mathrm{MHz}\right) \square 7.57-7.49(\mathrm{~m}, 4 \mathrm{H})$, 7.34-7.22 (m, $11 \mathrm{H}), 7.19(\mathrm{~d}, \mathrm{~J}=8.4 \mathrm{~Hz}, 2 \mathrm{H}), 6.81(\mathrm{~d}, \mathrm{~J}=8.4 \mathrm{~Hz}, 2 \mathrm{H}), 5.15(\mathrm{~s}, 1 \mathrm{H}), 4.38-4.29$ (m, $4 \mathrm{H}), 4.04(\mathrm{t}, \mathrm{J}=2.2 \mathrm{~Hz}, 1 \mathrm{H}), 3.75(\mathrm{~s}, 3 \mathrm{H}), 3.75-3.72(\mathrm{~m}, 1 \mathrm{H}), 3.48(\mathrm{dd}, \mathrm{J}=8.4,6.6 \mathrm{~Hz}, 2 \mathrm{H}), 3.11$ $(\mathrm{t}, \mathrm{J}=9.5 \mathrm{~Hz}, 1 \mathrm{H}), 3.07(\mathrm{t}, \mathrm{J}=11.4 \mathrm{~Hz}, 1 \mathrm{H}), 2.32-2.27(\mathrm{~m}, 1 \mathrm{H}), 2.25($ app. t, J = 4.8 Hz, $1 \mathrm{H})$, 2.01-1.92 (m, 2 H), 1.88-1.79 (m, 2 H), 1.72-1.68 (m, 1 H), 1.68 (s, $3 \mathrm{H}), 1.60-1.53$ (m, $4 \mathrm{H}), 1.05$ $(\mathrm{s}, 9 \mathrm{H}) ;{ }^{13} \mathrm{C} \mathrm{NMR}\left(\mathrm{CDCl}_{3}, 100 \mathrm{MHz}\right) \square 212.7,159.0,138.6,138.0,135.7,135.6,133.3,132.9$, $130.9,130.0,129.0,128.3,127.8,127.7,127.4,124.3,113.7,77.5,73.0,72.4,69.9,68.1,55.3$, 47.3, 45.8, 36.8, 36.1, 29.8, 27.4, 26.9, 22.4, 19.2; IR (neat) 3071, 3048, 2930, 2857, 1732, 1613, 1589, 1428, 1113, 1039, 702; HRMS (ESI) for $\mathrm{C}_{45} \mathrm{H}_{54} \mathrm{O}_{5} \mathrm{SiNa}[\mathrm{M}+\mathrm{Na}]^{+}$calcd. 725.3638, found 725.3645 

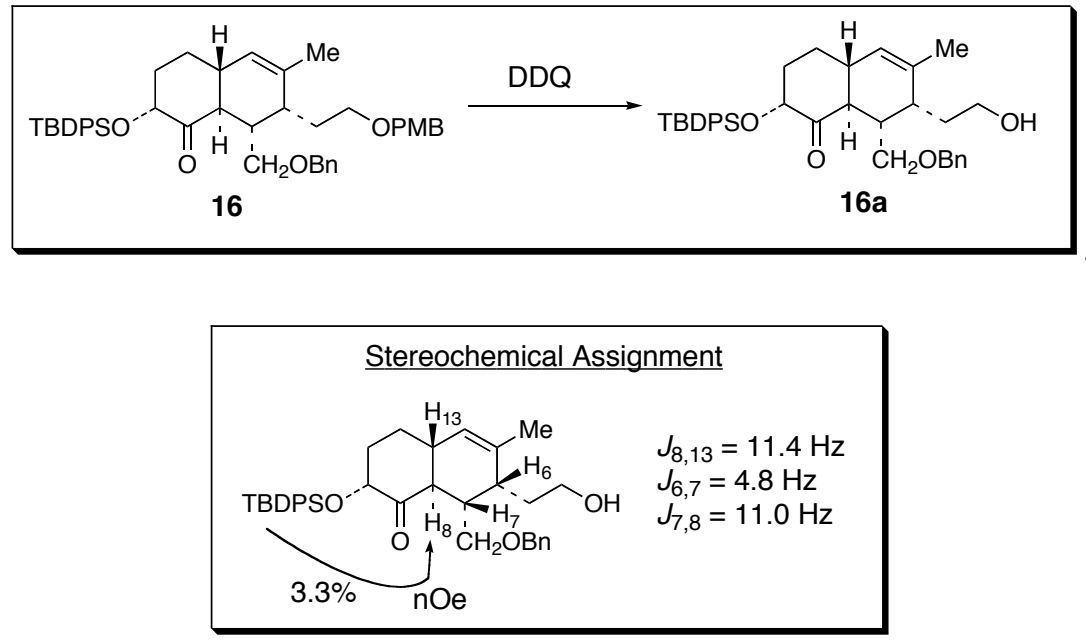

rac-(2R,4a $R, 7 R, 8 S, 8 \mathrm{a} S)-8$-benzyloxymethyl-2-(tert-butyldiphenylsilyloxy)-7-[2-

hydroxyethyl]-6-methyl-4,4a,7,8,8a-hexahydro- $2 H$-naphalen-1-one (16a). A solution of cycloadduct $16(7.5 \mathrm{mg}, 11 \square \mathrm{mol})$ in a mixture of $\mathrm{CH}_{2} \mathrm{Cl}_{2}(0.5 \mathrm{~mL})$ and $\mathrm{pH} 7$ buffer $(0.025 \mathrm{~mL})$ was treated with DDQ $(3.0 \mathrm{mg}, 13.1 \square \mathrm{mol})$ at room temperature. The mixture was stirred for $3 \mathrm{~h}$, then poured into a saturated aqueous solution of $\mathrm{NaHCO}_{3}(5 \mathrm{~mL})$ and extracted with $\mathrm{CH}_{2} \mathrm{Cl}_{2}(3 \times 2 \mathrm{~mL})$. The combined organic extracts were washed with brine, dried over $\mathrm{MgSO}_{4}$, filtered and evaporated. The crude product was purified by preparatory thin-layer chromatography on $\mathrm{SiO}_{2}(40 \%$ EtOAc/Hexane) to give $4.4 \mathrm{mg}(70 \%)$ of $16 \mathrm{a}$ as a clear oil: ${ }^{1} \mathrm{H} \mathrm{NMR}\left(\mathrm{CDCl}_{3}, 500 \mathrm{MHz}\right) \square 7.55-7.51$ (m, 4 H), 7.39-7.29 (m, 11 H), $5.13(\mathrm{~S}, 1 \mathrm{H}), 4.10$ (d, J = 4.4 Hz, 2 H), 4.04 (s, $1 \mathrm{H}), 3.84$ (dd, J = 9.9, 4.4 Hz, $1 \mathrm{H}), 3.66-3.58(\mathrm{~m}, 2 \mathrm{H}), 3.13$ (t, J = 10.3 Hz, $1 \mathrm{H}), 3.07$ (t, J = 11.0 Hz, $1 \mathrm{H}), 2.49$ (br. s, 1 H), 2.31 (ddd, J = 16.1, 11.0, 4.8 Hz, 1 H), 2.22 (d, J = 4.0 Hz, 1 H), 2.05-1.97 (m, 2 H), 1.89$1.80(\mathrm{~m}, 1 \mathrm{H}), 1.79-1.71(\mathrm{~m}, 1 \mathrm{H}), 1.68(\mathrm{~s}, 3 \mathrm{H}), 1.62-1.53(\mathrm{~m}, 3 \mathrm{H}), 1.52(\mathrm{~s}, 3 \mathrm{H}), 1.05(\mathrm{~s}, 9 \mathrm{H}) ;{ }^{13} \mathrm{C}$ NMR $\left(\mathrm{CDCl}_{3}, 100 \mathrm{MHz}\right) \square 212.8,168.3,138.7,135.7,135.6,133.2,130.0,128.4,128.0,127.8$, $127.7,123.8,77.5,73.2,67.9,63.1,47.4,45.0,36.7,36.5,36.1,33.0,27.4,26.9,22.5,19.2$; IR (neat) $3432,2931,2858,1720,1654,1428,1106,1094,1039,701$; HRMS (ESI) for $\mathrm{C}_{37} \mathrm{H}_{46} \mathrm{O}_{4} \mathrm{SiNa}$ $[\mathrm{M}+\mathrm{Na}]^{+}$calcd. 605.3063, found 605.3060. 


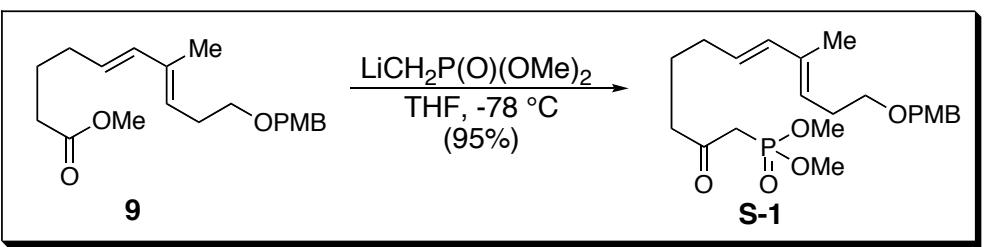

(6E,8E)-11-(4-methoxybenzyloxy)-8-methyl-2-oxo-undeca-6,8-dienyl-

dimethylphosphonate $(\mathbf{S}-1)$. To a solution of dimethyl methylphosphonate $(0.45 \mathrm{~mL}, 4.19 \mathrm{mmol})$ in THF $(10 \mathrm{~mL})$ cooled to $-78^{\circ} \mathrm{C}$ was added a $2.45 \mathrm{M}$ solution of $n \mathrm{BuLi}$ in hexane $(1.5 \mathrm{~mL}, 3.68$ mmol) dropwise. The resulting solution was stirred for $30 \mathrm{~min}$, after which a solution of ester 9 (348 $\mathrm{mg}, 1.05 \mathrm{mmol})$ in THF (1 mL) was added dropwise with a THF (1 mL) flask wash. The reaction was stirred for $2.5 \mathrm{~h}$, and a $10 \%$ aqueous solution of $\mathrm{K}_{2} \mathrm{HPO}_{4}(10 \mathrm{~mL})$ was added. The mixture was warmed to room temperature and extracted with $\mathrm{Et}_{2} \mathrm{O}(5 \mathrm{x} 10 \mathrm{~mL})$. The combined organic extracts were washed with brine, dried over $\mathrm{MgSO}_{4}$, filtered, and evaporated. Purification of the crude product by column chromatography on $\mathrm{SiO}_{2}(60 \%-100 \%$ EtOAc/Hexane) gave $402 \mathrm{mg}$ (95\%) of 11 as a clear oil: ${ }^{1} \mathrm{H} \mathrm{NMR}\left(\mathrm{CDCl}_{3}, 400 \mathrm{MHz}\right) \square 7.23(\mathrm{~d}, \mathrm{~J}=8.8 \mathrm{~Hz}, 2 \mathrm{H}), 6.84(\mathrm{~d}, \mathrm{~J}=8.8 \mathrm{~Hz}, 2 \mathrm{H})$, $6.02(\mathrm{~d}, \mathrm{~J}=15.4 \mathrm{~Hz}, 1 \mathrm{H}), 5.48(\mathrm{dt}, \mathrm{J}=15.4 \mathrm{~Hz}, 7.0 \mathrm{~Hz}, 1 \mathrm{H}), 5.36(\mathrm{t}, \mathrm{J}=7.3 \mathrm{~Hz}, 1 \mathrm{H}), 4.41(\mathrm{~s}, 2$ H), $3.78(\mathrm{~s}, 3 \mathrm{H}), 3.75(\mathrm{~d}, \mathrm{~J}=11.0 \mathrm{~Hz}, 6 \mathrm{H}), 3.43(\mathrm{t}, \mathrm{J}=7.0 \mathrm{~Hz}, 2 \mathrm{H}), 3.07(\mathrm{~s}, 1 \mathrm{H}), 3.02(\mathrm{~s}, 1 \mathrm{H})$, $2.58(\mathrm{t}, \mathrm{J}=7.0 \mathrm{~Hz}, 2 \mathrm{H}), 2.40(\mathrm{q}, \mathrm{J}=7.0 \mathrm{~Hz}, 2 \mathrm{H}), 2.07$ (q, J = 7.3 Hz, $2 \mathrm{H}), 1.69$ (s, $3 \mathrm{H}), 1.68-1.63$ (m, $2 \mathrm{H}) ;{ }^{13} \mathrm{C} \mathrm{NMR}\left(\mathrm{CDCl}_{3}, 100 \mathrm{MHz}\right) \square 159.0,135.4,135.0,130.4,129.1,126.5,126.4,113.6$, $72.4,69.3,55.1,43.3,43.2,41.8,40.6,31.7,28.7,23.0,12.4$; IR (neat) $2954,2854,1715,1613$, 1514, 1456, 1364, 1249, 1033, 818; HRMS (ESI) for $\mathrm{C}_{22} \mathrm{H}_{33} \mathrm{O}_{6} \mathrm{PNa}[\mathrm{M}+\mathrm{Na}]^{+}$calcd. 447.1912, found 447.1918 . 


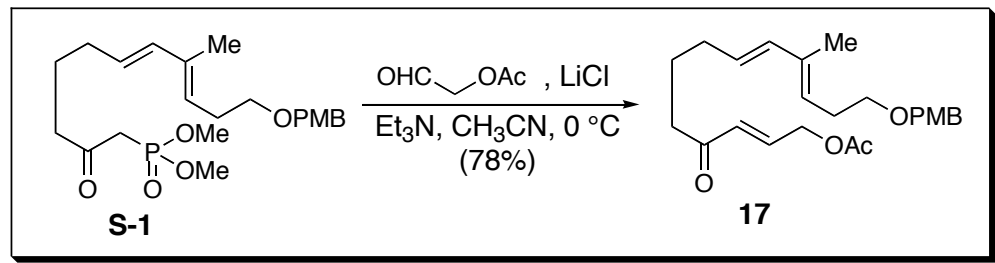

$(2 E, 8 E, 10 E)-1$-acetoxy-13-(4-methoxybenzyloxy)-10-methyl-trideca-2,8,10-trien-4-one

(17). $\mathrm{LiCl}(87.0 \mathrm{mg}, 2.06 \mathrm{mmol})$ was added to a stirred solution of $\mathrm{G}$-ketophosphonate $\mathbf{S - 1}$ (146 mg, $0.34 \mathrm{mmol})$ in $\mathrm{CH}_{3} \mathrm{CN}(3.4 \mathrm{~mL})$, and the resulting mixture was cooled to $0{ }^{\circ} \mathrm{C} . \mathrm{Et}_{3} \mathrm{~N}(0.17 \mathrm{~mL}, 1.20$ mmol) was added, and the mixture was stirred for 5 min before acetoxy acetaldehyde $(0.23 \mathrm{~mL}$, $1.65 \mathrm{mmol}$ ) was added dropwise. The reaction was stirred for $2 \mathrm{~h}$, quenched with a saturated aqueous solution of $\mathrm{NH}_{4} \mathrm{Cl}(10 \mathrm{~mL})$, and extracted with $\mathrm{CH}_{2} \mathrm{Cl}_{2}(3 \times 5 \mathrm{~mL})$. The combined organic extracts were washed with brine, dried over $\mathrm{MgSO}_{4}$, filtered, and evaporated. Purification of the crude product by column chromatography on $\mathrm{SiO}_{2}$ (25\% EtOAc/Hexane) gave $207 \mathrm{mg}$ (78\%) of $\mathbf{1 7}$ as a glass: ${ }^{1} \mathrm{H}$ NMR $\left(\mathrm{CDCl}_{3}, 500 \mathrm{MHz}\right) \square 7.26(\mathrm{~d}, \mathrm{~J}=8.4 \mathrm{~Hz}, 2 \mathrm{H}), 6.87(\mathrm{~d}, \mathrm{~J}=8.4 \mathrm{~Hz}, 2 \mathrm{H}), 6.78$ $(\mathrm{dt}, \mathrm{J}=16.1,4.8 \mathrm{~Hz}, 1 \mathrm{H}), 6.27(\mathrm{dt}, \mathrm{J}=15.8,1.8 \mathrm{~Hz}, 1 \mathrm{H}), 6.06(\mathrm{~d}, \mathrm{~J}=15.8 \mathrm{~Hz}, 1 \mathrm{H}), 5.52(\mathrm{dt}, \mathrm{J}=$ 15.4, 7.0 Hz, $1 \mathrm{H}), 5.39$ (t, J = 7.3 Hz, $1 \mathrm{H}), 4.74(\mathrm{dd}, \mathrm{J}=4.8,2.2 \mathrm{~Hz}, 2 \mathrm{H}), 4.45(\mathrm{~s}, 2 \mathrm{H}), 3.81(\mathrm{~s}, 3$ H), $3.46(\mathrm{t}, \mathrm{J}=7.0 \mathrm{~Hz}, 2 \mathrm{H}), 2.57(\mathrm{t}, \mathrm{J}=7.3 \mathrm{~Hz}, 2 \mathrm{H}), 2.43(\mathrm{q}, \mathrm{J}=7.3 \mathrm{~Hz}, 2 \mathrm{H}), 2.43(\mathrm{q}, \mathrm{J}=7.3 \mathrm{~Hz}$, $2 \mathrm{H}), 2.12$ (s, $3 \mathrm{H}), 2.13-2.09$ (m, $2 \mathrm{H}), 1.73$ (s, $3 \mathrm{H}), 1.76-1.70$ (m, $2 \mathrm{H}) ;{ }^{13} \mathrm{C}$ NMR $\left(\mathrm{CDCl}_{3}, 100\right.$ MHz) $\square 199.7,170.3,159.1,138.7,135.5,135.1,130.0,129.2,129.1,126.8,126.5,113.7,72.5$, 69.4, 62.7, 55.2, 39.8, 32.1, 28.8, 23.6, 20.7, 12.5; IR (neat) 2933, 2859, 1743, 1701, 1638, 1612, 1513, 1364, 1246, 1088, 1031; HRMS (ESI) for $\mathrm{C}_{24} \mathrm{H}_{32} \mathrm{O}_{5} \mathrm{Na}[\mathrm{M}+\mathrm{Na}]^{+}$calcd. 423.2147, found 423.2142. 


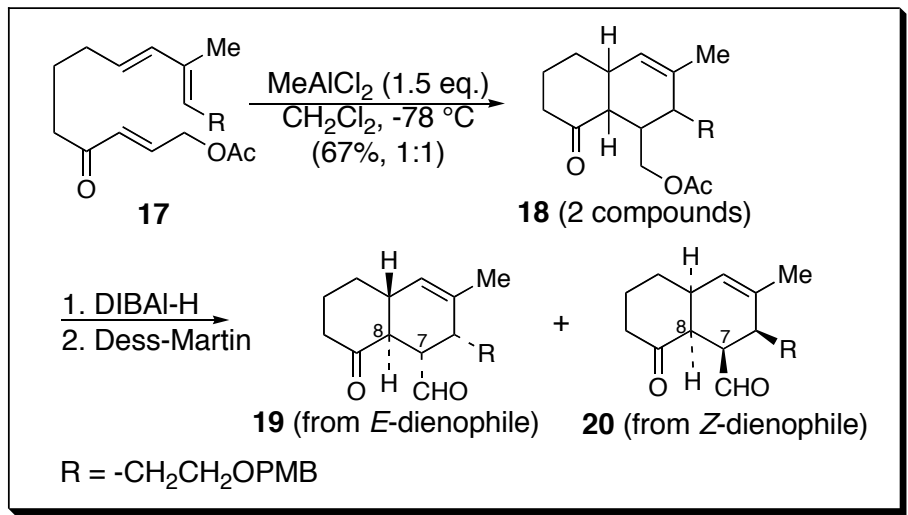

IMDA of 17. To a cooled $\left(-78{ }^{\circ} \mathrm{C}\right)$ solution of triene $17(46 \mathrm{mg}, 0.11 \mathrm{mmol})$ in $\mathrm{CH}_{2} \mathrm{Cl}_{2}(2.3$ $\mathrm{mL})$ was added dropwise a solution of $\mathrm{MeAlCl}_{2}(0.17 \mathrm{~mL}, 0.17 \mathrm{mmol})$ in hexanes. The reaction was stirred for $1.5 \mathrm{~h}$, and an additional portion of $\mathrm{MeAlCl}_{2}(0.04 \mathrm{~mL}, 0.04 \mathrm{mmol})$ was added. The reaction was stirred for an additional $1 \mathrm{~h}$, then a saturated aqueous solution of Rochelle's salt (5 $\mathrm{mL}$ ) was added, and the resulting mixture warmed to room temperature. The aqueous layer was extracted with $\mathrm{Et}_{2} \mathrm{O}(2 \times 5 \mathrm{~mL})$. The combined organic extracts were washed with brine, dried over $\mathrm{MgSO}_{4}$, filtered and evaporated. Purification of the crude product by thin-layer chromatography (eluted 3 x with $25 \%$ EtOAc/Hexane) gave partially purified samples of two cycloadducts: $14.7 \mathrm{mg}$ $(32 \%)$ of $\mathbf{1 8 a}$ and $16.1 \mathrm{mg}(35 \%)$ of $\mathbf{1 8 b}$.

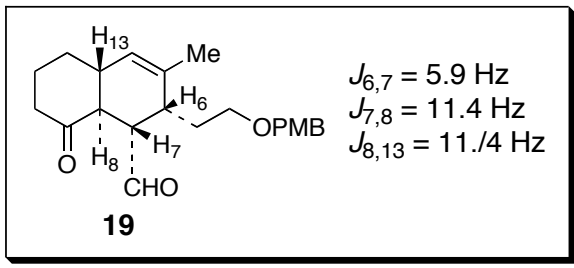

rac-(1S,2R,4aR,8aS)-2-[2-(4-methoxybenzyloxy)ethyl]-3-methyl-8-oxo-1,2,4a,5,6,7,8,8aoctahydro-napthalene-1-carboxaldehyde $(19)$. To a cooled $\left(-78{ }^{\circ} \mathrm{C}\right)$ solution of cycloadduct $18 \mathbf{a}$ (14.0 mg, $36.0 \square \mathrm{mol})$ in $\mathrm{CH}_{2} \mathrm{Cl}_{2}(1 \mathrm{~mL})$ was added a $1 \mathrm{M}$ solution of DIBAl-H $(0.1 \mathrm{~mL}, 0.1 \mathrm{mmol})$ in hexane. The reaction was warmed to room temperature and a saturated aqueous solution of 
Rochelle's salt $(5 \mathrm{~mL})$ was added. The mixture was stirred for 30 min then extracted with $\mathrm{Et}_{2} \mathrm{O}(3 \mathrm{x}$ $3 \mathrm{~mL}$ ). The combined organic extracts were washed with brine, dried over $\mathrm{MgSO}_{4}$, filtered and evaporated. The residue was redissolved in $\mathrm{CH}_{2} \mathrm{Cl}_{2}(0.5 \mathrm{~mL})$ and treated with 1 drop of pyridine and the Dess-Martin periodinane $(38 \mathrm{mg}, 87 \square \mathrm{mol})$. The resulting reaction mixture was stirred for $1 \mathrm{~h}$ before being diluted with $\mathrm{Et}_{2} \mathrm{O}(5 \mathrm{~mL})$ and a 1:1 mixture of saturated aqueous $\mathrm{NaHCO}_{3}$ and $\mathrm{Na}_{2} \mathrm{~S}_{2} \mathrm{O}_{3}$ $(5 \mathrm{~mL})$. The aqueous layer was extracted with $\mathrm{Et}_{2} \mathrm{O}(2 \times 5 \mathrm{~mL})$ and the combined organic extracts were washed with brine, dried over $\mathrm{MgSO}_{4}$, filtered and evaporated. The crude product could only be partially purified by preparatory thin-layer chromatography on $\mathrm{SiO}_{2}(30 \% \mathrm{EtOAc} / \mathrm{Hexane})$ to give $10.0 \mathrm{mg}(80 \%)$ of 19 as a clear oil: ${ }^{1} \mathrm{H} \mathrm{NMR}\left(\mathrm{CDCl}_{3}, 400 \mathrm{MHz}\right) \square 9.76(\mathrm{~d}, \mathrm{~J}=2.2 \mathrm{~Hz}, 1 \mathrm{H})$, $7.22(\mathrm{~d}, \mathrm{~J}=8.4 \mathrm{~Hz}, 2 \mathrm{H}), 6.86(\mathrm{~d}, \mathrm{~J}=8.8 \mathrm{~Hz}, 2 \mathrm{H}), 5.28(\mathrm{~s}, 1 \mathrm{H}), 4.37(\mathrm{q}, \mathrm{J}=9.2 \mathrm{~Hz}, 2 \mathrm{H}), 3.80$ (s, 3 H), 3.41-3.28 (m, $2 \mathrm{H}), 2.82(\mathrm{ddd}, \mathrm{J}=11.4,5.5,2.2 \mathrm{~Hz}, 1 \mathrm{H}), 2.73(\mathrm{t}, \mathrm{J}=11.4 \mathrm{~Hz}, 1 \mathrm{H}), 2.55-2.53$ (br. s, $1 \mathrm{H}), 2.48-2.32(\mathrm{~m}, 2 \mathrm{H}), 2.14-2.04(\mathrm{~m}, 3 \mathrm{H}), 1.93-1.86$ (m, $2 \mathrm{H}), 1.70-1.62(\mathrm{~m}, 1 \mathrm{H}), 1.50$ $(\mathrm{dd}, \mathrm{J}=12.8,4.0 \mathrm{~Hz}, 1 \mathrm{H}), 1.44(\mathrm{dd}, \mathrm{J}=12.6,3.7 \mathrm{~Hz}, 1 \mathrm{H}), 1.32-1.22(\mathrm{~m}, 1 \mathrm{H}), 1.25(\mathrm{~s}, 3 \mathrm{H}) ;{ }^{13} \mathrm{C}$ $\operatorname{NMR}\left(\mathrm{CDCl}_{3}, 125 \mathrm{MHz}\right) \square 203.5,129.1,125.2,113.8,94.4,76.6,72.5,68.6,55.3,49.6,49.7,44.0$, 41.6, 36.6, 32.1, 30.4, 29.7, 21.8, 1.0; HRMS (ESI) for $\mathrm{C}_{22} \mathrm{H}_{28} \mathrm{O}_{4} \mathrm{Na}[\mathrm{M}+\mathrm{Na}]^{+}$calcd. 379.1885, found 379.1890 .

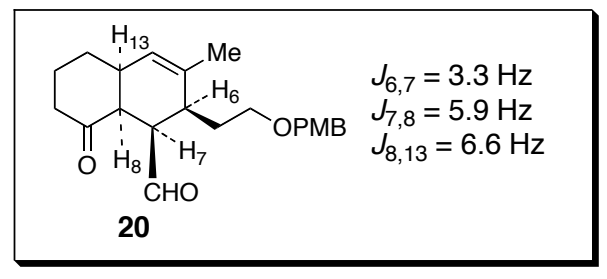

rac-(1R,2S,4aS,8aS)-2-[2-(4-methoxybenzyloxy)ethyl]-3-methyl-8-oxo-1,2,4a,5,6,7,8,8aoctahydro-napthalene-1-carboxaldehyde $(\mathbf{2 0})$. To a cooled $\left(-78^{\circ} \mathrm{C}\right)$ solution of cycloadduct $\mathbf{1 8 b}$ (16.1 mg, $40.2 \square \mathrm{mol})$ in $\mathrm{CH}_{2} \mathrm{Cl}_{2}(1 \mathrm{~mL})$ was added a $1 \mathrm{M}$ solution of DIBAl-H $(0.12 \mathrm{~mL}, 0.12$ mmol) in hexane. The reaction was warmed to room temperature and a saturated aqueous solution 
of Rochelle's salt $(5 \mathrm{~mL})$ was added. The mixture was stirred for 30 min then extracted with $\mathrm{Et}_{2} \mathrm{O}(3$ x $3 \mathrm{~mL}$ ). The combined organic extracts were washed with brine, dried over $\mathrm{MgSO}_{4}$, filtered and evaporated. The residue was redissolved in $\mathrm{CH}_{2} \mathrm{Cl}_{2}(0.5 \mathrm{~mL})$ and treated with 1 drop of pyridine and the Dess-Martin periodinane (44 mg, $100 \square \mathrm{mol}$ ). The resulting reaction mixture was stirred for $1 \mathrm{~h}$ before being diluted with $\mathrm{Et}_{2} \mathrm{O}(5 \mathrm{~mL})$ and a 1:1 mixture of saturated aqueous $\mathrm{NaHCO}_{3}$ and $\mathrm{Na}_{2} \mathrm{~S}_{2} \mathrm{O}_{3}$ $(5 \mathrm{~mL})$. The aqueous layer was extracted with $\mathrm{Et}_{2} \mathrm{O}(2 \times 5 \mathrm{~mL})$ and the combined organic extracts were washed with brine, dried over $\mathrm{MgSO}_{4}$, filtered and evaporated. The crude product could only be partially purified by preparatory thin-layer chromatography on $\mathrm{SiO}_{2}(30 \%$ EtOAc/Hexane) to give $8.1 \mathrm{mg}(57 \%)$ of $\mathbf{2 0}$ as a clear oil: ${ }^{1} \mathrm{H} \mathrm{NMR}\left(\mathrm{CDCl}_{3}, 400 \mathrm{MHz}\right) \square 9.49(\mathrm{~d}, \mathrm{~J}=1.1 \mathrm{~Hz}, 1 \mathrm{H}), 7.24$ $(\mathrm{d}, \mathrm{J}=6.2 \mathrm{~Hz}, 2 \mathrm{H}), 6.86(\mathrm{~d}, \mathrm{~J}=8.4 \mathrm{~Hz}, 2 \mathrm{H}), 5.24(\mathrm{~s}, 1 \mathrm{H}), 4.45(\mathrm{~A}$ of ABX, J = 19.4, $11.4 \mathrm{~Hz}, 1$ H), $4.37(\mathrm{~B}$ of ABX, J = 19.4, $11.4 \mathrm{~Hz}, 1 \mathrm{H}), 3.79(\mathrm{~s}, 3 \mathrm{H}), 3.64-3.53(\mathrm{~m}, 2 \mathrm{H}), 3.23(\mathrm{t}, \mathrm{J}=4.0 \mathrm{~Hz}, 1$ H), $2.86(\mathrm{t}, \mathrm{J}=5.9,1 \mathrm{H}), 2.68-2.66$ (br. s, $2 \mathrm{H}), 2.43-2.38(\mathrm{~m}, 2 \mathrm{H}), 2.32-2.24(\mathrm{~m}, 2 \mathrm{H}), 2.04-1.98$ (m, $2 \mathrm{H}), 1.71(\mathrm{~s}, 3 \mathrm{H}), 1.54-1.46(2 \mathrm{H}) ;{ }^{13} \mathrm{C}$ NMR $\left(\mathrm{CDCl}_{3}, 125 \mathrm{MHz}\right) \square 211.5$, 203.7, 159.2, 136.7, $130.5,129.5,126.0,113.8,72.6,67.3,55.3,48.4,47.0,40.6,34.9,34.0,31.1,29.5,22.1,22.0$; HRMS (ESI) for $\mathrm{C}_{22} \mathrm{H}_{28} \mathrm{O}_{4} \mathrm{Na}[\mathrm{M}+\mathrm{Na}]^{+}$calcd. 379.1885, found 379.1886.

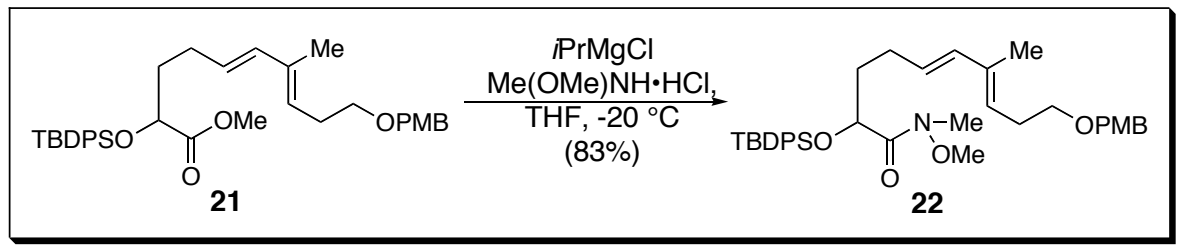

(5E,7E)-2-(tert-butyldiphenylsilyloxy)-10-(4-methoxybenzyloxy)-7-methyl-deca-5,7-

dienoic acid methoxy-methyl-amide (22). A sample of impure methyl ester 21 (496 mg, ca. 0.846 mmol, as prepared previously for the synthesis of 11), was dissolved in THF (2.1 mL). $\mathrm{Me}(\mathrm{OMe}) \mathrm{NH} \bullet \mathrm{HCl}(128 \mathrm{mg}, 1.31 \mathrm{mmol})$ was added to the solution, and the resulting suspension was cooled to $-20^{\circ} \mathrm{C}$. A $2 \mathrm{M}$ solution of $i \operatorname{PrMgCl}(1.27 \mathrm{~mL}, 2.54 \mathrm{mmol}) \mathrm{in}_{2} \mathrm{Et}_{2} \mathrm{O}$ was added 
dropwise to the suspension. After being stirred for $1 \mathrm{~h}$ at $-20^{\circ} \mathrm{C}$, the reaction was quenched by the addition of a saturated aqueous solution of $\mathrm{NH}_{4} \mathrm{Cl}(5 \mathrm{~mL})$ and warmed to room temperature. The mixture was extracted with $\mathrm{Et}_{2} \mathrm{O}(3 \times 5 \mathrm{~mL})$, and the combined organic extracts were washed with brine, dried over $\mathrm{Na}_{2} \mathrm{SO}_{4}$ and evaporated. The crude product was purified by column chromatography on $\mathrm{SiO}_{2}(25 \% \mathrm{EtOAc} / \mathrm{Hexane})$ to give $432 \mathrm{mg}(83 \%)$ of 22 as a clear oil: ${ }^{1} \mathrm{H}$ NMR $\left(\mathrm{CDCl}_{3}, 500 \mathrm{MHz}\right) \square 7.72-7.69(\mathrm{~m}, 4 \mathrm{H}), 7.43-7.34(\mathrm{~m}, 6 \mathrm{H}), 7.27(\mathrm{~d}, \mathrm{~J}=8.8 \mathrm{~Hz}, 2 \mathrm{H}), 6.88(\mathrm{~d}, \mathrm{~J}=$ $8.8 \mathrm{~Hz}, 2 \mathrm{H}), 5.99(\mathrm{~d}, \mathrm{~J}=15.8 \mathrm{~Hz}, 1 \mathrm{H}), 5.47(\mathrm{dt}, \mathrm{J}=15.8,6.6 \mathrm{~Hz}, 1 \mathrm{H}), 5.34(\mathrm{t}, \mathrm{J}=6.6 \mathrm{~Hz}, 1 \mathrm{H})$, 4.50 (br. t, J = 5.1 Hz, $1 \mathrm{H}), 4.46(\mathrm{~s}, 2 \mathrm{H}), 3.80(\mathrm{~s}, 2 \mathrm{H}), 3.46$ (t, J = 7.0 Hz, $2 \mathrm{H}), 3.07$ (br. s, $3 \mathrm{H}$ ), 2.98 (br. s, 3 H), 2.43 (q, J = 6.7 Hz, 2 H), 2.19 (q, J = 6.6 Hz, 2 H), 1.86-1.81 (m, 2 H), 1.69 (s, 3 $\mathrm{H}), 1.10(\mathrm{~s}, 9 \mathrm{H}) ;{ }^{13} \mathrm{C} \mathrm{NMR}\left(\mathrm{CDCl}_{3}, 100 \mathrm{MHz}\right) \square 159.1,136.1,135.9,135.0,133.7,133.4,130.5$, $129.6,129.5,127.5,127.3,127.0,126.9,126.2,117.7,72.5,69.4,60.5,55.2,34.5,28.8,28.0,26.9$, 19.4, 12.4; IR (neat) 2933, 2857, 1679, 1613, 1514, 1428, 1174, 1112, 1037; HRMS (ESI) for $\mathrm{C}_{37} \mathrm{H}_{49} \mathrm{NO}_{5} \mathrm{SiNa}[\mathrm{M}+\mathrm{Na}]^{+}$calcd. 638.3278, found 638.3300.

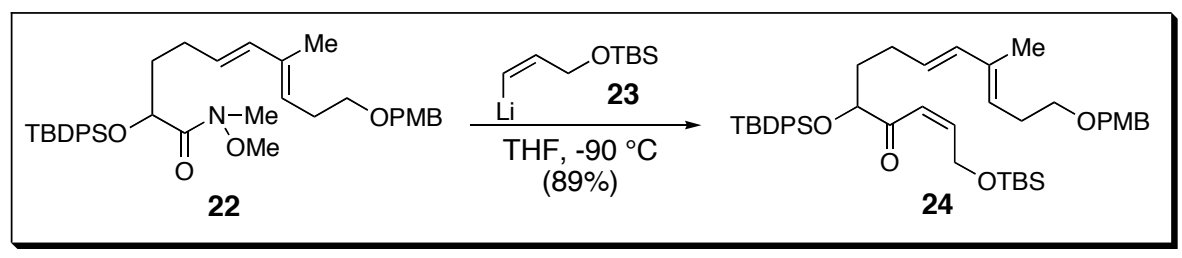

(2Z,8E,10E)-1-(tert-butyldimethylsilyloxy)-5-(tert-butyldiphenylsilyloxy)-13-(4-

methoxybenzyloxy)-10-methyl-deca-2,8,10-trien-4-one $(24)$. To a cooled $\left(-78{ }^{\circ} \mathrm{C}\right)$ solution of (1Z)-1-iodo-3-(tert-butyldimethylsilyloxy)-1-propene (811 $\mathrm{mg}, 2.71 \mathrm{mmol})$ in $\mathrm{Et}_{2} \mathrm{O}(9 \mathrm{~mL})$ was added a $2.33 \mathrm{M}$ solution of $n \mathrm{BuLi}(1.17 \mathrm{~mL}, 2.71 \mathrm{mmol})$ in hexanes dropwise over $10 \mathrm{~min}$. The reaction was stirred at $-78^{\circ} \mathrm{C}$ for $1 \mathrm{~h}$, then cooled to $-95^{\circ} \mathrm{C}$. A solution of Weinreb amide $22(558$ $\mathrm{mg}, 0.91 \mathrm{mmol})$ in $\mathrm{Et}_{2} \mathrm{O}(1.5 \mathrm{~mL})$ was added to the reaction mixture dropwise with a $\mathrm{Et}_{2} \mathrm{O}(0.5 \mathrm{~mL})$ syringe wash, maintaining an internal temperature $<-90^{\circ} \mathrm{C}$. After the addition was complete, the 
mixture was warmed to $-78^{\circ} \mathrm{C}$ and stirred for $1 \mathrm{~h}$. The reaction was then added to a cooled $\left(0^{\circ} \mathrm{C}\right)$ saturated aqueous solution of $\mathrm{NH}_{4} \mathrm{Cl}(20 \mathrm{~mL})$, and the mixture was warmed to room temperature. The aqueous layer was extracted with $\mathrm{Et}_{2} \mathrm{O}(3 \times 10 \mathrm{~mL})$, and the combined organic extracts were washed with brine, dried over $\mathrm{MgSO}_{4}$, filtered and evaporated. Purification of the crude product by column chromatography on $\mathrm{SiO}_{2}(10 \%$ EtOAc/Hexane) gave $586 \mathrm{mg}(89 \%)$ of 24 as a clear oil containing a small amount (ca. 3-5\%) of 3-(tert-butyldimethylsilyloxy)-1-propene. Characterization data for 24: ${ }^{1} \mathrm{H} \mathrm{NMR}\left(\mathrm{CDCl}_{3}, 500 \mathrm{MHz}\right) \square 7.66(\mathrm{dd}, \mathrm{J}=7.8,1.2 \mathrm{~Hz}, 2 \mathrm{H}), 7.59$ (dd, J = 7.8, 1.2 Hz, $2 \mathrm{H}), 7.45-7.33(\mathrm{~m}, 6 \mathrm{H}), 7.27(\mathrm{~d}, \mathrm{~J}=8.5 \mathrm{~Hz}, 2 \mathrm{H}), 6.89(\mathrm{~d}, \mathrm{~J}=8.5 \mathrm{~Hz}, 2 \mathrm{H}), 6.53(\mathrm{dt}, \mathrm{J}=11.7,2.4$ Hz, $1 \mathrm{H}), 6.36$ (dt, J = 11.4, 4.4 Hz, $1 \mathrm{H}), 5.95$ (d, J = $15.4 \mathrm{~Hz}, 1 \mathrm{H}), 5.39$ (t, J = 6.8 Hz, $1 \mathrm{H})$, 5.37$5.33(\mathrm{~m}, 1 \mathrm{H}), 4.64$ (ddd, J = 7.1, 4.2, $2.7 \mathrm{~Hz}, 2 \mathrm{H}), 4.46(\mathrm{~s}, 2 \mathrm{H}), 4.16(\mathrm{t}, \mathrm{J}=6.1 \mathrm{~Hz}, 1 \mathrm{H}), 3.81(\mathrm{~s}, 3$ H), 3.46 (t, J = 7.1 Hz, 2 H), 2.43 (q, J = 6.8 Hz, 2 H), 2.10-1.96 (m, 2 H), 1.75-1.69 (m, 1 H), 1.66 (s, $3 \mathrm{H}), 1.66-1.60(\mathrm{~m}, 1 \mathrm{H}), 1.12(\mathrm{~s}, 9 \mathrm{H}), 0.93(\mathrm{~s}, 9 \mathrm{H}), 0.09(\mathrm{~s}, 3 \mathrm{H}), 0.08(\mathrm{~s}, 3 \mathrm{H}) ;{ }^{13} \mathrm{C}$ NMR $\left(\mathrm{CDCl}_{3}, 100 \mathrm{MHz}\right) \square 202.2,159.4,153.6,136.1,135.5,135.3,133.7,133.2,130.8,130.1,129.5$, $127.9,126.8,126.7,120.8,114.0,78.8,72.8,69.7,63.2,55.5,35.2,29.1,27.8,27.3,26.2,26.1$, 19.6, 18.5, 12.7, -5.0; IR (neat) 2955, 2931, 2894, 2857, 1690, 1613, 1588, 1512, 1472, 1256, 1096, 838, 702; HRMS (ESI) for $\mathrm{C}_{44} \mathrm{H}_{62} \mathrm{O}_{5} \mathrm{Si}_{2} \mathrm{Na}[\mathrm{M}+\mathrm{Na}]^{+}$calcd. 749.4034, found 749.4039.

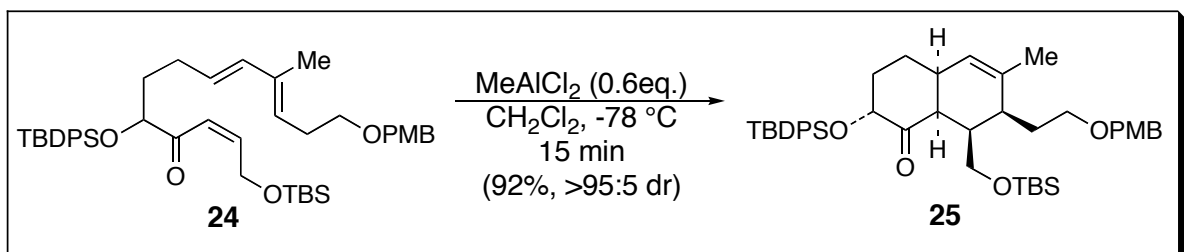

rac-(2R,4aS,7S,8R,8aS)-8-(tert-butyldimethylsilyloxymethyl)-2-(tertbutyldiphenylsilyloxy)-7-[2-(4-methoxybenzyloxy)-ethyl]-6-methyl-3,4,4a,7,8,8a-hexahydro-2Hnaphthalen-1-one (25). To a cooled $\left(-78{ }^{\circ} \mathrm{C}\right)$ solution of triene $25(410 \mathrm{mg}, 0.56 \mathrm{mmol})$ in $\mathrm{CH}_{2} \mathrm{Cl}_{2}$ $(11 \mathrm{~mL})$ was added a $1 \mathrm{M}$ solution of $\mathrm{MeAlCl}_{2}(0.34 \mathrm{~mL}, 0.34 \mathrm{mmol})$ dropwise over $10 \mathrm{~min}$. The 
reaction was stirred for 15 min before being quenched by the addition of a saturated aqueous solution of Rochelle's salt $(10 \mathrm{~mL})$. The resulting mixture was diluted with ether, warmed to room temperature, and stirred for $1 \mathrm{~h}$. The mixture was extracted with $\mathrm{Et}_{2} \mathrm{O}(3 \times 10 \mathrm{~mL})$ and the combined organic extracts were washed with brine, dried over $\mathrm{MgSO}_{4}$, filtered and evaporated. Purification of the crude product by column chromatography on $\mathrm{SiO}_{2}(10 \%$ EtOAc/Hexane) gave $377 \mathrm{mg}(92 \%)$ of 25 contaminated with a small amount (ca. 3-5\%) of 3-(tert-butyldimethylsilyloxy)-1-propene from the previous reaction. Characterization data for $25:{ }^{1} \mathrm{H} \mathrm{NMR}\left(\mathrm{CDCl}_{3}, 400 \mathrm{MHz}\right) \square 7.61(\mathrm{~d}, \mathrm{~J}=7.3$ Hz, 4 H), 7.38-7.29 (m, 6 H), 7.21 (d, J = 8.4 Hz, 2 H), $6.83(\mathrm{~d}, \mathrm{~J}=8.4 \mathrm{~Hz}, 2 \mathrm{H}), 5.01$ (s, $1 \mathrm{H}), 4.36$ (s, $2 \mathrm{H}), 4.01$ (t, J = 5.1 Hz, $1 \mathrm{H}), 3.77$ (br. s, $5 \mathrm{H}), 3.38$ (t, J = $7.0 \mathrm{~Hz}, 2 \mathrm{H}), 3.05$ (br. s, $1 \mathrm{H}), 2.62$ (br. s, $1 \mathrm{H}), 2.14$ (s, $1 \mathrm{H}), 2.02-2.01(\mathrm{~m}, 1 \mathrm{H}), 1.93(\mathrm{dd}, \mathrm{J}=14.3,6.6 \mathrm{~Hz}, 1 \mathrm{H}), 1.72-1.58(\mathrm{~m}, 2 \mathrm{H})$, $1.56(\mathrm{~s}, 4 \mathrm{H}), 1.43(\mathrm{dd}, \mathrm{J}=13.6,4.8 \mathrm{~Hz}, 1 \mathrm{H}), 1.32-1.24(\mathrm{~m}, 1 \mathrm{H}), 1.04(\mathrm{~s}, 9 \mathrm{H}), 0.81(\mathrm{~s}, 9 \mathrm{H}),-0.06$ $(\mathrm{s}, 6 \mathrm{H}) ;{ }^{13} \mathrm{C} \mathrm{NMR}\left(\mathrm{CDCl}_{3}, 125 \mathrm{MHz}\right) \square 210.7,159.0,135.9,135.7,134.0,133.2,130.9,129.7$, $129.0,127.5,124.9,113.7,76.2,72.3,70.8,63.1,55.2,43.7,38.6,37.0,30.6,29.7,26.9,26.0,25.5$, 22.4, 19.3, 18.2, -5.4; IR (neat) 2930, 2856, 1718, 1613, 1513, 1472, 1428, 1248, 1102, 836, 777, 702; HRMS (ESI) for $\mathrm{C}_{44} \mathrm{H}_{62} \mathrm{O}_{5} \mathrm{Si}_{2} \mathrm{Na}[\mathrm{M}+\mathrm{Na}]^{+}$calcd. 749.4034, found 749.4054.

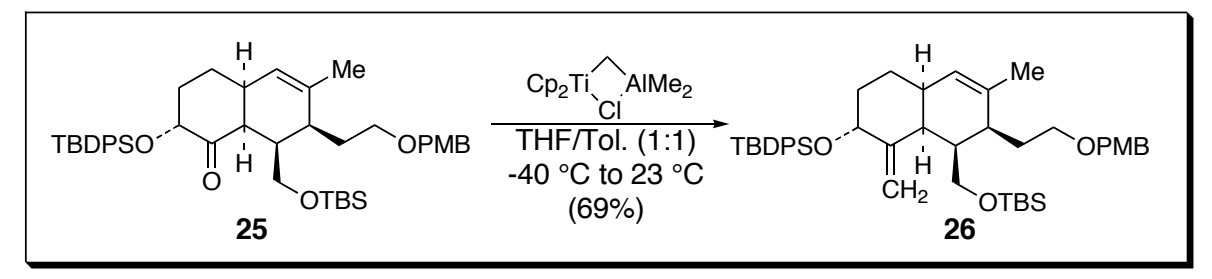

rac-(3R,4aS,5R,6S,8aS)-5-(tert-butyldimethylsilyloxymethyl)-3-(tert-

\section{butyldiphenylsilyloxy)-6-[2-(4-methoxybenzyloxy)-ethyl]-7-methyl-4-methylene-}

1,2,3,4,4a,5,6,8a-octahydronaphthalene (26). To a cooled $\left(-78^{\circ} \mathrm{C}\right)$ solution of cycloadduct 25 (98.0 $\mathrm{mg}, 0.13 \mathrm{mmol})$ in THF $(0.9 \mathrm{~mL})$ and toluene $(0.5 \mathrm{~mL})$ was added a $0.5 \mathrm{M}$ solution of Tebbe reagent $(0.4 \mathrm{~mL}, 0.2 \mathrm{mmol})$ in toluene dropwise over $1 \mathrm{~min}$. The resulting mixture was allowed to 
warm to $0{ }^{\circ} \mathrm{C}$ over $30 \mathrm{~min}$ and stirred an additional $1.5 \mathrm{~h}$. Additional Tebbe reagent $(0.2 \mathrm{~mL}, 0.1$ mmol) was added and the mixture stirred again for $1.5 \mathrm{~h}$. The reaction was quenched by the addition of $\mathrm{MeOH}$ and EtOAc, stirred at room temperature for $30 \mathrm{~min}$, then filtered through celite. The filtrate was evaporated, adsorbed onto $\mathrm{SiO}_{2}$, and purified by column chromatography on $\mathrm{SiO}_{2}(5 \%$ EtOAc/Hexane) to give $67.6 \mathrm{mg}$ (69\%) of $\mathbf{2 6}$ as a clear oil: ${ }^{1} \mathrm{H}$ NMR $\left(\mathrm{CDCl}_{3}, 500 \mathrm{MHz}\right) \square 7.70-7.68$ (m, 4 H), 7.43-7.40 (m, 2 H), 7.38-7.34 (m, 4 H), 7.28 (d, J = 8.3 Hz, 2 H), 6.90 (d, J = 8.5 Hz, 2 H), $5.56(\mathrm{t}, \mathrm{J}=2.0 \mathrm{~Hz}, 1 \mathrm{H}), 5.17(\mathrm{~s}, 1 \mathrm{H}), 5.06(\mathrm{~s}, 1 \mathrm{H}), 4.48(\mathrm{~A}$ of AB, J = 11.5 Hz, $1 \mathrm{H}), 4.42-4.39$ $(\mathrm{m}, 1 \mathrm{H}), 4.38(\mathrm{~B}$ of $\mathrm{AB}, \mathrm{J}=11.7 \mathrm{~Hz}, 1 \mathrm{H}), 3.82(\mathrm{~s}, 3 \mathrm{H}), 3.60-3.49(\mathrm{~m}, 4 \mathrm{H}), 2.94(\mathrm{dd}, \mathrm{J}=$ 7.1, 3.9 Hz, 1 H), 2.46 (br. s, 1 H), 2.17 (br. s, 1 H), 1.99 (ddd, J = 7.8, 3.9, 3.9 Hz, 1 H), 1.82-1.77 (m, 2 H), $1.63(\mathrm{~s}, 3 \mathrm{H}), 1.58(\mathrm{p}, \mathrm{J}=6.3 \mathrm{~Hz}, 1 \mathrm{H}), 1.50-1.45(\mathrm{~m}, 1 \mathrm{H}), 1.34-1.26(\mathrm{~m}, 2 \mathrm{H}), 1.11(\mathrm{~s}, 9 \mathrm{H}), 0.82$ (s, $9 \mathrm{H}),-0.12$ (s, $3 \mathrm{H}),-0.13$ (s, $3 \mathrm{H}) ;{ }^{13} \mathrm{C} \mathrm{NMR}\left(\mathrm{CDCl}_{3}, 125 \mathrm{MHz}\right) \square 159.0,152.1,135.8,135.7$, 135.1, 134.9, 134.0, 130.9, 129.6, 129.2, 127.6, 127.4, 126.2, 113.7, 110.8, 72.9, 72.5, 69.6, 62.2, $55.2,44.7,39.7,36.7,34.4,29.2,28.4,27.0,25.9,22.0,19.4,18.1,-5.7$; IR (neat) $3071,2930,2857$, $1613,1513,1472,1428,1249,1104,837,702$; HRMS (ESI) for $\mathrm{C}_{45} \mathrm{H}_{64} \mathrm{O}_{4} \mathrm{Si}_{2} \mathrm{Na}[\mathrm{M}+\mathrm{Na}]^{+}$calcd. 747.4241, found 747.4265. 

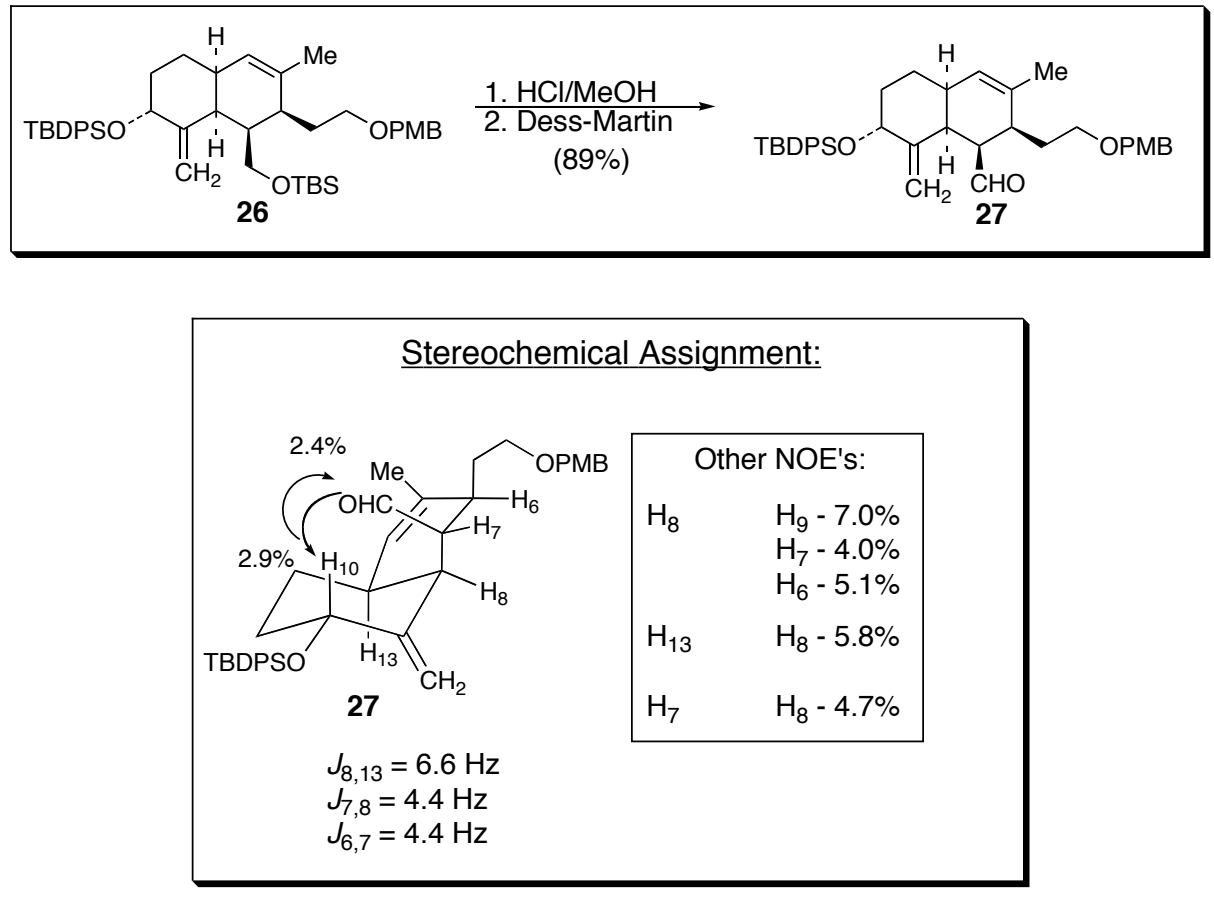

rac-(1R,2S,4aS,7R,8aS)-7-(tert-butyldiphenylsilyloxy)-2-[2-(4-methoxybenzyloxy)-ethyl]-3methyl-8-methylene-1,2,4a,5,6,7,8,8a-octahydronaphthalene-1-carboxaldehyde (27). To a solution of cis-decalin $26(54.8 \mathrm{mg}, 75.6 \square \mathrm{mol})$ in $\mathrm{MeOH}(0.4 \mathrm{~mL})$ was added a solution of $\mathrm{MeOH}(0.95 \mathrm{~mL}$ of $1 \% 6 \mathrm{~N} \mathrm{HCl}$ in $\mathrm{MeOH}$ ). The resulting mixture was stirred for $1.5 \mathrm{~h}$, and a saturated aqueous solution of $\mathrm{NaHCO}_{3}(5 \mathrm{~mL})$ was added. The mixture was extracted with $\mathrm{Et}_{2} \mathrm{O}(3 \times 5 \mathrm{~mL})$, and the combined organic extracts were washed with brine, dried over $\mathrm{MgSO}_{4}$, filtered and evaporated. The residue was redissolved in $\mathrm{CH}_{2} \mathrm{Cl}_{2}(1 \mathrm{~mL})$ and cooled to $0{ }^{\circ} \mathrm{C}$. A drop of pyridine was added, followed by the Dess-Martin periodinane $(65.0 \mathrm{mg}, 0.15 \mathrm{mmol})$, and the reaction was stirred for 10 min. At this time, $\mathrm{H}_{2} \mathrm{O}$-saturated $\mathrm{CH}_{2} \mathrm{Cl}_{2}(0.5 \mathrm{~mL})$ was added dropwise and the reaction warmed to room temperature. After being stirred for $1 \mathrm{~h}$, the reaction mixture was poured into a 1:1 mixture of saturated aqueous $\mathrm{NaHCO}_{3} / \mathrm{Na}_{2} \mathrm{~S}_{2} \mathrm{O}_{3}(10 \mathrm{~mL})$ and extracted with $\mathrm{Et}_{2} \mathrm{O}(3$ x $5 \mathrm{~mL})$. The combined organic extracts were washed with brine, dried over $\mathrm{MgSO}_{4}$, filtered and evaporated. Purification of the crude product by column chromatography on $\mathrm{SiO}_{2}(10 \%$ EtOAc/Hexane) gave $41.1 \mathrm{mg}(89 \%)$ of 27 as a clear oil: ${ }^{1} \mathrm{H} \mathrm{NMR}\left(\mathrm{CDCl}_{3}, 500 \mathrm{MHz}\right) \square 9.62(\mathrm{~d}, \mathrm{~J}=5.4 \mathrm{~Hz}, 1 \mathrm{H}), 7.72$ (dd, J = 7.8, 1.2 
Hz, 2 H), 7.67 (dd, J = 7.6, 1.0 Hz, 2 H), 7.46-7.36 (m, 6 H), $7.26(d, J=8.3 \mathrm{~Hz}, 2 \mathrm{H}), 6.90(\mathrm{~d}, \mathrm{~J}=$ $8.3 \mathrm{~Hz}, 2 \mathrm{H}), 5.52(\mathrm{~s}, 1 \mathrm{H}), 5.39$ (s, $1 \mathrm{H}), 5.05(\mathrm{~s}, 1 \mathrm{H}), 4.46$ (A of AB, J = 11.5 Hz, $1 \mathrm{H}$ ), 4.39 (B of $\mathrm{AB}, \mathrm{J}=11.2 \mathrm{~Hz}, 1 \mathrm{H}), 4.12($ app. d, J = $8.8 \mathrm{~Hz}, 1 \mathrm{H}), 3.81(\mathrm{~s}, 3 \mathrm{H}), 3.51-3.46(\mathrm{~m}, 1 \mathrm{H}), 3.41(\mathrm{dt}, \mathrm{J}=$ 9.0, $8.3 \mathrm{~Hz}, 1 \mathrm{H}$ ), 3.08 (br. s, $1 \mathrm{H}$ ), 2.67-2.65 (br. s, $1 \mathrm{H}), 2.60$ (q, J = 4.6 Hz, $1 \mathrm{H}$ ), 2.25 (br. s, $1 \mathrm{H}$ ), $2.13(\mathrm{ddd}, \mathrm{J}=12.9,7.3,7.3 \mathrm{~Hz}, 1 \mathrm{H}), 1.73(\mathrm{~s}, 3 \mathrm{H}), 1.62-1.59$ (m, $2 \mathrm{H}), 1.42-1.36(\mathrm{~m}, 1 \mathrm{H}), 1.32-$ $1.26(\mathrm{~m}, 1 \mathrm{H}), 1.10(\mathrm{~s}, 9 \mathrm{H}), 0.83(\mathrm{qd}, \mathrm{J}=16.6,3.2 \mathrm{~Hz}, 1 \mathrm{H}) ;{ }^{13} \mathrm{C} \mathrm{NMR}\left(\mathrm{CDCl}_{3}, 125 \mathrm{MHz}\right) \square 205.8$, 159.2, 151.6, 135.8, 135.7, 134.7, 133.5, 133.3, 130.4, 129.6, 129.5, 129.3, 127.6, 127.4, 126.8, $113.8,110.3,72.7,72.0,67.1,56.0,55.2,48.1,38.1,37.1,35.5,29.9,29.0,27.1,21.5,19.5 ;$ IR (neat) $2931,2858,1713,1612,1513,1428,1248,1111,703$; HRMS (ESI) for $\mathrm{C}_{39} \mathrm{H}_{48} \mathrm{O}_{4} \mathrm{SiNa}$ $[\mathrm{M}+\mathrm{Na}]^{+}$calcd. 631.3220, found 631.3224.

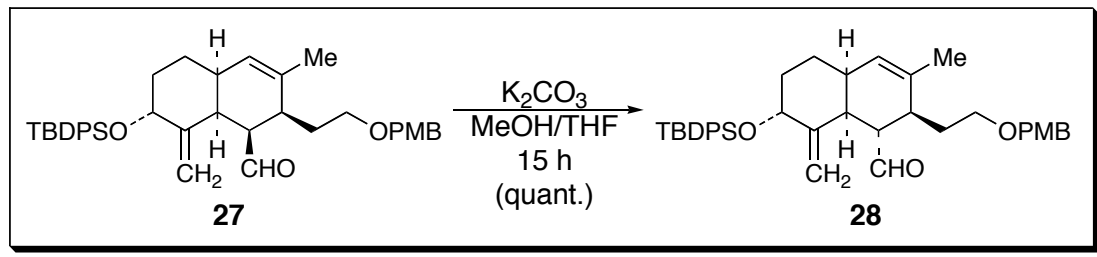

rac-(1S,2S,4aS,7R,8aS)-7-(tert-butyldiphenylsilyloxy)-2-[2-(4-methoxybenzyloxy)ethyl]-3-methyl-8-methylene-1,2,4a,5,6,7,8,8a-octahydronaphthalene-1-carboxaldehyde (28). Aldehyde $27(38.7 \mathrm{mg}, 63.6 \square \mathrm{mol})$ was dissolved in a mixture of $\mathrm{MeOH}(1 \mathrm{~mL})$ and $\mathrm{THF}(0.5 \mathrm{~mL})$ and treated with $\mathrm{K}_{2} \mathrm{CO}_{3}$ (ca. 20-30 mg), and the resulting mixture was stirred for $16 \mathrm{~h}$, then filtered. The filtrate was evaportated, and the residue was redisssolved in $\mathrm{Et}_{2} \mathrm{O}$ and filtered again. Evaporation of the filtrate gave $38.6 \mathrm{mg}$ (quant.) of 28 as a clear oil: ${ }^{1} \mathrm{H} \mathrm{NMR}\left(\mathrm{CDCl}_{3}, 500 \mathrm{MHz}\right)$ $\square 9.24(\mathrm{~d}, \mathrm{~J}=2.4 \mathrm{~Hz}, 1 \mathrm{H}), 7.71(\mathrm{~d}, \mathrm{~J}=7.8 \mathrm{~Hz}, 2 \mathrm{H}), 7.64(\mathrm{~d}, \mathrm{~J}=7.6 \mathrm{~Hz}, 2 \mathrm{H}), 7.43-7.37$ (m, $6 \mathrm{H})$, $7.16(\mathrm{~d}, \mathrm{~J}=8.3 \mathrm{~Hz}, 2 \mathrm{H}), 6.80(\mathrm{~d}, \mathrm{~J}=8.3 \mathrm{~Hz}, 2 \mathrm{H}), 5.43-5.40(\mathrm{~m}, 2 \mathrm{H}), 4.86(\mathrm{~s}, 1 \mathrm{H}), 4.35(\mathrm{dd}, \mathrm{J}=$ 11.2, $4.9 \mathrm{~Hz}, 1 \mathrm{H}), 4.27$ (s, $2 \mathrm{H}), 3.77$ (s, $3 \mathrm{H}), 3.30-3.22(\mathrm{~m}, 2 \mathrm{H}), 2.70-2.68(\mathrm{~m}, 1 \mathrm{H}), 2.57-2.54$ (m, $2 \mathrm{H}), 2.04(\mathrm{dd}, \mathrm{J}=11.5,5.1 \mathrm{~Hz}, 1 \mathrm{H}), 1.79-1.69(\mathrm{~m}, 2 \mathrm{H}), 1.61(\mathrm{~s}, 3 \mathrm{H}), 1.59-1.53(\mathrm{~m}, 2 \mathrm{H})$, 
1.37-1.25 (m, $1 \mathrm{H}), 1.08$ (s, $9 \mathrm{H}), 1.09-0.98(\mathrm{~m}, 1 \mathrm{H}) ;{ }^{13} \mathrm{C} \mathrm{NMR}\left(\mathrm{CDCl}_{3}, 125 \mathrm{MHz}\right) \square 204.3,159.1$, $149.9,135.9,135.7,134.5,133.6,133.5,130.3,129.7,129.6,129.3,127.7,127.5,127.3,113.7$, 109.3, 72.5, 71.0, 66.9, 55.2, 49.0, 45.9, 38.4, 36.5, 36.1, 30.4, 28.5, 27.0, 21.4, 19.4; IR (neat) 2931, 2858, 1724, 1613, 1513, 1428, 1248, 1118, 1037, 703; HRMS (ESI) for $\mathrm{C}_{39} \mathrm{H}_{48} \mathrm{O}_{4} \mathrm{SiNa}$ $[\mathrm{M}+\mathrm{Na}]^{+}$calcd. 631.3220, found 631.3239.

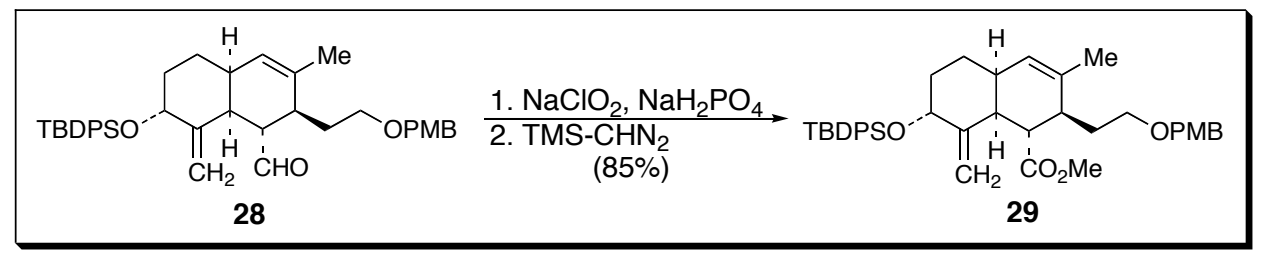

rac-(1S,2S,4aS,7R,8aS)-7-(tert-butyldiphenylsilyloxy)-2-[2-(4-methoxybenzyloxy)ethyl]-3-methyl-8-methylene-1,2,4a,5,6,7,8,8a-octahydronaphthalene-1-carboxylic acid methyl ester (29). Aldehyde 28 (38.0 mg, $62.4 \square \mathrm{mol})$ was dissolved in a mixture of $t \mathrm{BuOH}(1.5 \mathrm{~mL})$ and 2 methyl-2-butene $(0.6 \mathrm{~mL})$ and treated with $0.3 \mathrm{~mL}$ of a $\mathrm{NaClO}_{2} / \mathrm{NaH}_{2} \mathrm{PO}_{4}$ oxidant solution (prepared by mixing $375 \mathrm{mg}$ of $\mathrm{NaClO}_{2}$ and $375 \mathrm{mg}$ of $\mathrm{NaH}_{2} \mathrm{PO}_{4}$ in $2.5 \mathrm{~mL} \mathrm{H}_{2} \mathrm{O}$ ). The mixture was stirred for 30 min, and three drops of $\mathrm{SMe}_{2}$ were added via pipette. The mixture was stirred for an additional 30 min, diluted with brine $(0.5 \mathrm{~mL})$ and extracted with $\mathrm{CH}_{2} \mathrm{Cl}_{2}(3 \times 1 \mathrm{~mL})$. The combined organic extracts were evaporated. The residue was redissolved in a mixture of benzene $(1 \mathrm{~mL})$ and $\mathrm{MeOH}$ $(0.3 \mathrm{~mL})$, and a $2 \mathrm{M}$ solution of TMS- $\mathrm{CHN}_{2}(0.05 \mathrm{~mL}, 0.1 \mathrm{mmol})$ in $\mathrm{Et}_{2} \mathrm{O}$ was added dropwise. The resulting mixture was stirred for $10 \mathrm{~min}$ and then evaporated. Purification of the crude product by column chromatography on $\mathrm{SiO}_{2}(10 \% \mathrm{EtOAc} / \mathrm{Hexane})$ gave $33.8 \mathrm{mg}(85 \%)$ of 29 as a clear oil: ${ }^{1} \mathrm{H}$ $\operatorname{NMR}\left(\mathrm{CDCl}_{3}, 500 \mathrm{MHz}\right) \square 7.71(\mathrm{~d}, \mathrm{~J}=6.8 \mathrm{~Hz}, 2 \mathrm{H}), 7.67(\mathrm{~d}, \mathrm{~J}=6.6 \mathrm{~Hz}, 2 \mathrm{H}), 7.43-7.34(\mathrm{~m}, 6 \mathrm{H})$, $7.20(\mathrm{~d}, \mathrm{~J}=8.3 \mathrm{~Hz}, 2 \mathrm{H}), 6.81(\mathrm{~d}, \mathrm{~J}=8.5 \mathrm{~Hz}, 2 \mathrm{H}), 5.39(\mathrm{~d}, \mathrm{~J}=5.6 \mathrm{~Hz}, 1 \mathrm{H}), 5.36(\mathrm{t}, \mathrm{J}=2.2 \mathrm{~Hz}, 1$ H), $4.86(\mathrm{~s}, 1 \mathrm{H}), 4.41(\mathrm{dd}, \mathrm{J}=11.5,4.9 \mathrm{~Hz}, 1 \mathrm{H}), 4.35(\mathrm{~A}$ of $\mathrm{AB}, \mathrm{J}=11.5 \mathrm{~Hz}, 1 \mathrm{H}), 4.32(\mathrm{~B}$ of $\mathrm{AB}$, $\mathrm{J}=11.5 \mathrm{~Hz}, 1 \mathrm{H}), 3.77(\mathrm{~s}, 3 \mathrm{H}), 3.55(\mathrm{~s}, 3 \mathrm{H}), 3.34(\mathrm{q}, \mathrm{J}=8.5 \mathrm{~Hz}, 1 \mathrm{H}), 3.29-3.24(\mathrm{~m}, 1 \mathrm{H}), 2.70$ 
$(\mathrm{dd}, \mathrm{J}=11.2,4.9 \mathrm{~Hz}, 1 \mathrm{H}), 2.61(\mathrm{t}, \mathrm{J}=10.3 \mathrm{~Hz}, 1 \mathrm{H}), 2.59(\mathrm{~s}, 1 \mathrm{H}), 2.04(\mathrm{dd}, \mathrm{J}=11.5,6.8 \mathrm{~Hz}, 1 \mathrm{H})$, 1.80-1.65 (m, $2 \mathrm{H}), 1.61(\mathrm{~s}, 3 \mathrm{H}), 1.58-1.54(\mathrm{~m}, 1 \mathrm{H}), 1.49(\mathrm{dd}, \mathrm{J}=13.9,3.2 \mathrm{~Hz}, 1 \mathrm{H}), 1.43-1.20$ (m, $1 \mathrm{H}), \quad 1.08(\mathrm{~s}, \quad 9 \mathrm{H}), \quad 0.95-0.86 \quad(\mathrm{~m}, \quad 1 \quad \mathrm{H}) ;{ }^{13} \mathrm{C} \quad \mathrm{NMR} \quad\left(\mathrm{CDCl}_{3}, \quad 125 \mathrm{MHz}\right)$ $\square 175.8,159.3,150.9,136.1,135.1,134.1,133.8,130.8,129.8,129.4,127.8,127.7,127.5,114.0$, $108.8,77.5,71.2,67.1,55.5,51.5,47.6,46.3,40.2,38.2,36.8,30.6,28.7,27.2,21.5,19.7$; IR (neat) 2931, 2857, 1736, 1513, 1428, 1248, 1164, 1112, 703; HRMS (ESI) for $\mathrm{C}_{40} \mathrm{H}_{50} \mathrm{O}_{5} \mathrm{SiNa}[\mathrm{M}+\mathrm{Na}]^{+}$ calcd. 661.3325 , found 661.3329.
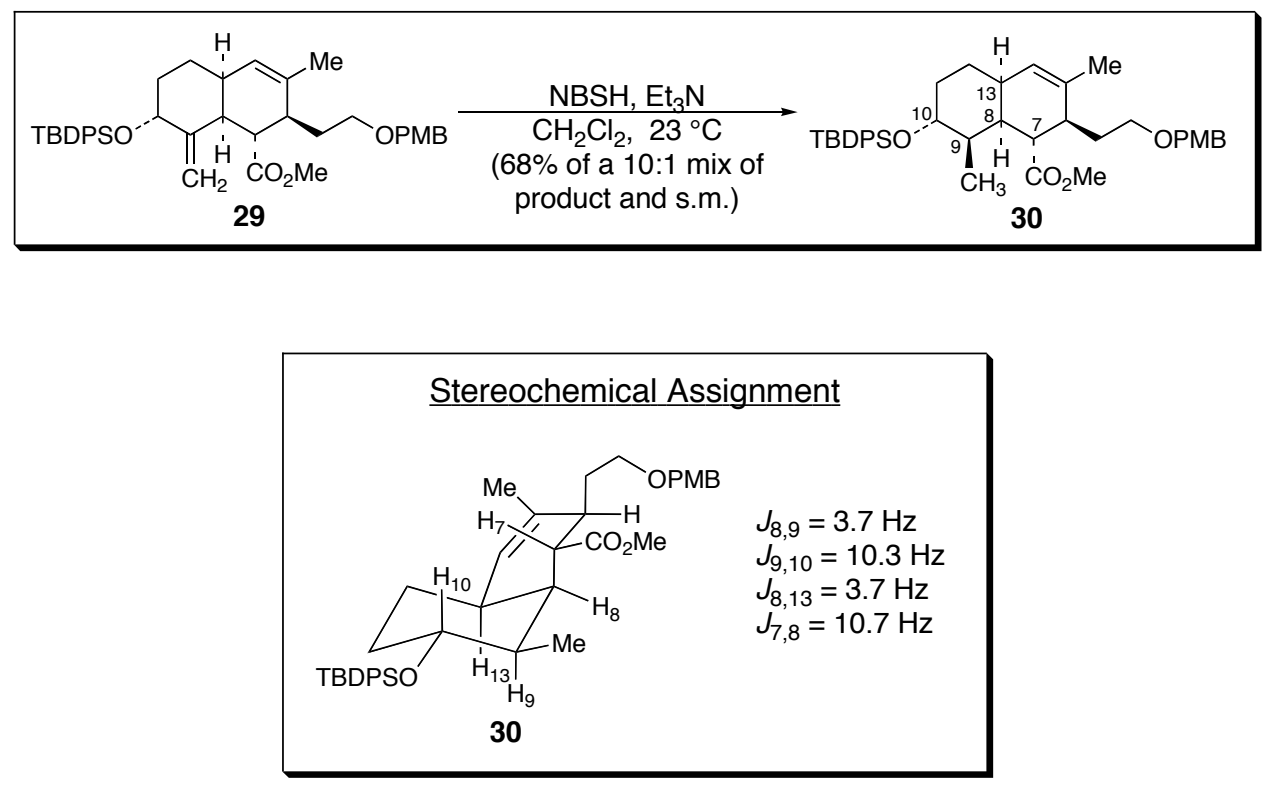

rac-(1R,2S,4aR,7R,8R,8aR)-7-(tert-butyldiphenylsilyloxy)-2-[2-(4-methoxybenzyloxy)ethyl]-3,8-dimethyl-1,2,4a,5,6,7,8,8a-octahydronaphthalene-1-carboxylic acid methyl ester (30). To a solution of $29(21.0 \mathrm{mg}, 32.9 \square \mathrm{mol})$ in $\mathrm{CH}_{2} \mathrm{Cl}_{2}(0.2 \mathrm{~mL})$ was added $o$ nitrobenzenesulfonylhydrazide $(71.3 \mathrm{mg}, 329 \square \mathrm{mol})$ and $\mathrm{Et}_{3} \mathrm{~N}$ (55 $\left.\square \mathrm{L}, 394 \square \mathrm{mol}\right)$. The resulting mixture was stirred for $20 \mathrm{~h}$, and additional $o$-nitrobenzenesulfonylhydrazide (35 mg, $162 \square \mathrm{mol}$ ) and Et3N (30 \L, $215 \square$ mol) was added. The reaction was stirred for another $4 \mathrm{~h}$, after which a saturated aqueous solution of $\mathrm{NaHCO}_{3}(1 \mathrm{~mL})$ was added. This mixture was extracted with EtOAc 
( $5 \times 1 \mathrm{~mL}$ ), and the combined organic extracts were dried over $\mathrm{Na}_{2} \mathrm{SO}_{4}$ and evaporated. Purification of the crude product by thin-layer chromatography on $\mathrm{SiO}_{2}(25 \% \mathrm{EtOAc} / \mathrm{Hexane})$ gave $14.3 \mathrm{mg}$ (68\%) of 30 as a clear oil: ${ }^{1} \mathrm{H} \mathrm{NMR}\left(\mathrm{CDCl}_{3}, 500 \mathrm{MHz}\right) \square 7.70(\mathrm{dd}, \mathrm{J}=12.0,7.3 \mathrm{~Hz}, 4 \mathrm{H}), 7.64-7.34$ $(\mathrm{m}, 6 \mathrm{H}), 7.21(\mathrm{~d}, \mathrm{~J}=8.1 \mathrm{~Hz}, 2 \mathrm{H}), 6.83(\mathrm{~d}, \mathrm{~J}=7.8 \mathrm{~Hz}, 2 \mathrm{H}), 5.40(\mathrm{~d}, \mathrm{~J}=5.9 \mathrm{~Hz}, 1 \mathrm{H}), 4.36($ A of $\mathrm{AB}, \mathrm{J}=11.5 \mathrm{~Hz}, 1 \mathrm{H}), 4.32(\mathrm{~B}$ of $\mathrm{AB}, \mathrm{J}=11.5 \mathrm{~Hz}, 1 \mathrm{H}), 3.83(\mathrm{td}, \mathrm{J}=10.7,4.2 \mathrm{~Hz}, 1 \mathrm{H}), 3.78(\mathrm{~s}, 3$ H), 3.57 (s, 3 H), 3.35 (q, J = 6.8 Hz, 1 H), $3.23(\mathrm{q}, \mathrm{J}=0.5 \mathrm{~Hz}, 1 \mathrm{H}), 2.48(\mathrm{t}, \mathrm{J}=10.3 \mathrm{~Hz}, 1 \mathrm{H}), 2.46$ (s, $1 \mathrm{H}), 2.12-2.10(\mathrm{~m}, 1 \mathrm{H}), 1.94$ (app. d, J = $6.3 \mathrm{~Hz}, 1 \mathrm{H}), 1.85-1.76(\mathrm{~m}, 2 \mathrm{H}), 1.65-1.62(\mathrm{~m}, 2 \mathrm{H})$, 1.57 (s, $3 \mathrm{H}), 1.45$ (app. d, J = 13.9 Hz, $1 \mathrm{H}), 1.31-1.23(\mathrm{~m}, 1 \mathrm{H}), 1.04$ (s, $9 \mathrm{H}), 0.95$ (d, J = 7.3 Hz, $3 \mathrm{H}), 0.86(\mathrm{qd}, \mathrm{J}=14.6,4.4 \mathrm{~Hz}, 1 \mathrm{H}) ;{ }^{13} \mathrm{C} \mathrm{NMR}\left(\mathrm{CDCl}_{3}, 125 \mathrm{MHz}\right) \square 177.7,159.0,136.0,135.3$, 134.3, 132.8, 130.6, 129.4, 129.3, 129.1, 128.1, 127.4, 127.3, 113.7, 72.5, 66.7, 55.3, 51.5, 44.4, 43.1, 42.5, 42.0, 38.6, 36.2, 29.5, 28.7, 27.0, 21.0, 19.5, 15.8; IR (neat) 3071, 2931, 2853, 1735, $1613,1513,1428,1248,1111,1087,821,703$; HRMS (ESI) for $\mathrm{C}_{40} \mathrm{H}_{52} \mathrm{O}_{5} \mathrm{SiNa}[\mathrm{M}+\mathrm{Na}]^{+}$calcd. 663.3482, found 663.3490 . 